\title{
Synthesis of Archaebacterial Bipolar Lipid Analogues: A Way to Versatile Drug/Gene Delivery Systems
}

Mickaëlle Brard, Céline Lainé, Gildas Réthoré, Isabelle Laurent, Cécile Neveu, Loïc Lemiègre, and Thierry Benvegnu*

UMR CNRS 6226 "Sciences Chimiques de Rennes”, Equipe "Chimie Organique et Supramoléculaire”, Ecole Nationale Supérieure de Chimie de Rennes, Av. Général Leclerc, 35700 Rennes, France

* To whom correspondence should be addressed. Tel: (33) (0)2 232380 60. Fax: (33) (0)2 23238046. E-mail: Thierry.Benvegnu@ensc-rennes.fr

\section{Supporting Information.}

$\begin{array}{ll}\text { Preparation of compound 14, 15, } 8 & \text { S2 }\end{array}$

Copies of ${ }^{1} \mathrm{H}$ and ${ }^{13} \mathrm{C}$ NMR spectra of compound $\mathbf{2} \quad$ S4

Copies of ${ }^{1} \mathrm{H}$ and ${ }^{13} \mathrm{C}$ NMR spectra of compound $\mathbf{3} \quad$ S5

Copies of ${ }^{1} \mathrm{H}$ and ${ }^{13} \mathrm{C}$ NMR spectra of compound 4 and 5a $\quad$ S6

Copies of ${ }^{1} \mathrm{H}$ and ${ }^{13} \mathrm{C}$ NMR spectra of compound $\mathbf{5 b} \quad$ S7

Copies of ${ }^{1} \mathrm{H}$ and ${ }^{13} \mathrm{C}$ NMR spectra of compound 6 (protected) S8

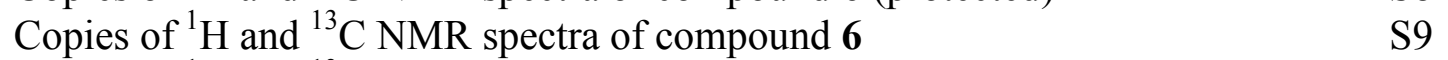

Copies of ${ }^{1} \mathrm{H}$ and ${ }^{13} \mathrm{C}$ NMR spectra of compound 7 (protected) $\quad \mathrm{S} 10$

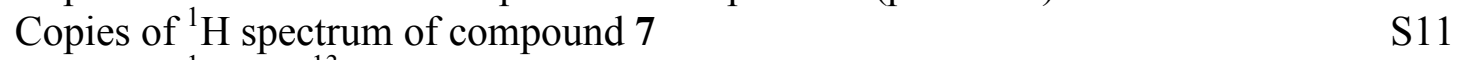

Copies of ${ }^{1} \mathrm{H}$ and ${ }^{13} \mathrm{C}$ NMR spectra of compound 9a $\quad$ S12

Copies of ${ }^{1} \mathrm{H}$ and ${ }^{13} \mathrm{C}$ NMR spectra of compound $\mathbf{1 8} \quad \mathrm{S} 13$

Copies of ${ }^{1} \mathrm{H}$ and ${ }^{13} \mathrm{C}$ NMR spectra of compound $19 \quad \mathrm{~S} 14$

Copies of ${ }^{1} \mathrm{H}$ and ${ }^{13} \mathrm{C}$ NMR spectra of compound 20a $\quad \mathrm{S} 15$

Copies of ${ }^{1} \mathrm{H}$ and ${ }^{13} \mathrm{C}$ NMR spectra of compound 20b $\quad$ S16

Copies of ${ }^{1} \mathrm{H}$ and ${ }^{13} \mathrm{C}$ NMR spectra of compound 22a $\quad$ S17

Copies of ${ }^{1} \mathrm{H}$ and ${ }^{13} \mathrm{C}$ NMR spectra of compound 22b $\quad$ S18

Copies of ${ }^{1} \mathrm{H}$ and ${ }^{13} \mathrm{C}$ NMR spectra of compound $23 \quad$ S19

Copies of ${ }^{1} \mathrm{H}$ and ${ }^{13} \mathrm{C}$ NMR spectra of compound $25 \quad$ S20

Copies of ${ }^{1} \mathrm{H}$ and ${ }^{13} \mathrm{C}$ NMR spectra of compound 28a $\quad$ S21

Copies of ${ }^{1} \mathrm{H}$ and ${ }^{13} \mathrm{C}$ NMR spectra of compound $\mathbf{2 8 b} \quad$ S22

General. All commercially available chemicals were used without further purification, and solvents were carefully dried and distilled prior to use. Unless otherwise noted, nonaqueous reactions were carried out under a nitrogen atmosphere. Analytical TLC was performed on Merck 60 F254 silica gel nonactivated plates. A solution of $5 \% \mathrm{H}_{2} \mathrm{SO}_{4}$ in EtOH was used to develop the plates. Merck $60 \mathrm{H}(5-40$ $\mu \mathrm{m})$ silica gel was used for column chromatography. ${ }^{1} \mathrm{H}$ and ${ }^{13} \mathrm{C}$ NMR spectra were recorded at 400 and 
$100 \mathrm{MHz}$, respectively. Fast-atom bombardement (FAB) mass spectra were acquired on a MS/MS TOF mass spectrometer with $m$-nitrobenzylic alcohol as the matrix.

\section{1-O-benzyl-sn-glycerol $14^{1,2}$}

To a suspension of sodium hydride (60\% in mineral oil, $12.2 \mathrm{~g}, 300 \mathrm{mmol}, 1.35$ equiv) in dry THF/DMF (210 mL, 3:1) was added dropwise a solution of $(R)$-solketal 11 (30 g, $227 \mathrm{mmol}, 1$ equiv) in dry THF $(50 \mathrm{~mL})$. A solution of benzyl bromide $(32.4 \mathrm{~mL}, 272.5 \mathrm{mmol}, 1.2$ equiv) in THF $(20 \mathrm{~mL})$ was added and then tetrabutylammonium iodine was added. The reaction mixture was stirred at room temperature overnight under nitrogen atmosphere. $\mathrm{Et}_{2} \mathrm{O}$ and water were added and the aqueous phase was extracted with diethylic ether. The combined organic phases were washed with $5 \% \mathrm{Na}_{2} \mathrm{~S}_{2} \mathrm{O}_{3}$, dried $\left(\mathrm{MgSO}_{4}\right)$ and concentrated under reduced pressure. The residue (45 $\left.\mathrm{g}, 89 \%\right)$ was stirred in the presence of IR-120 Amberlite resine $(20 \mathrm{~g})$ in $\mathrm{MeOH}(175 \mathrm{~mL})$ at reflux for $6 \mathrm{~h}$. The resin was filtered and the solvent was evaporated under reduced pressure. The residue was purified by flash chromatography on silica gel $\left(\mathrm{CH}_{2} \mathrm{Cl}_{2} / \mathrm{MeOH}\right.$ : 1:0 then 8:2) to yield $14(35 \mathrm{~g}, 85 \%)$ as a colorless oil. $\mathrm{R}_{\mathrm{f}}=0.5$ EtOAc. $[\alpha]_{\mathrm{D}}^{20}:-5.4^{\circ}$ (pure), litt. ${ }^{1}:-5.5^{\circ}$ (pure). ${ }^{1} \mathrm{H}$ NMR $\left(\mathrm{CDCl}_{3}, 400 \mathrm{MHz}\right) \delta(\mathrm{ppm}): 2.77(\mathrm{~s}, 1 \mathrm{H}), 3.34(\mathrm{~s}, 1 \mathrm{H})$, 3.56-3.64 (m, 2H), 3.65-3.70 (dd, $J=4.0,11.7 \mathrm{~Hz}, 1 \mathrm{H}), 3.74-3.78(\mathrm{dd}, J=4.0,11.4 \mathrm{~Hz}, 1 \mathrm{H}), 3.96-3.99$ $(\mathrm{m}, 1 \mathrm{H}), 4.62(\mathrm{~s}, 2 \mathrm{H}), 7.43(\mathrm{~m}, 5 \mathrm{H}) .{ }^{13} \mathrm{C} \mathrm{NMR}\left(\mathrm{CDCl}_{3}, 100 \mathrm{MHz}\right) \delta(\mathrm{ppm}): 64.4,71.2,72.1,73.9,127.8$, $128.0,128.5,137.7$.

\section{1-O-benzyl-3-O-trityl-sn-glycerol $15^{2}$}

A mixture of diol 14 (20.1 g, $110 \mathrm{mmol}, 1$ equiv), triethylamine (61.5 mL, $441 \mathrm{mmol}, 4$ equiv), DMAP (1.35 g, $11 \mathrm{mmol}, 0.1$ equiv) and trityle chloride (37 g, $132 \mathrm{mmol}, 1.2$ equiv) in dry THF (150 $\mathrm{mL}$ ) was stirred at reflux for $24 \mathrm{~h}$. Water and $\mathrm{Et}_{2} \mathrm{O}$ were added and the aqueous phase was extracted with $\mathrm{Et}_{2} \mathrm{O}$, and the combined organic phases were dried $\left(\mathrm{MgSO}_{4}\right)$ and concentrated under reduced pressure. The residue was purified by flash chromatography on silica gel (PE/EtOAc: 98:2 then 90:10) then (EtOAc/MeOH: 2:1) to yield 15 (32 g, 68\%) as a white solid. $\mathrm{R}_{\mathrm{f}}=0.7$ (PE/EtOAc: 8:2). mp: $75^{\circ} \mathrm{C}$ (Hexane $\left./ i-\operatorname{Pr}_{2} \mathrm{O}\right)$, litt. $^{2}: 71-73.5^{\circ} \mathrm{C} .[\alpha]^{20}{ }_{\mathrm{D}}:+6.6^{\circ}$ (c 2.01, benzene), litt. ${ }^{61}:+6.3^{\circ}$ (c 5.05, benzene). ${ }^{1} \mathrm{H}$ NMR $\left(\mathrm{CDCl}_{3}, 400 \mathrm{MHz}\right) \delta(\mathrm{ppm}):$ 2.46-2.48 (d, $\left.J=5.1 \mathrm{~Hz}, 1 \mathrm{H}\right), 3.18-3.25(\mathrm{~m}, 2 \mathrm{H}), 3.53-3.62(\mathrm{~m}, 2 \mathrm{H})$, 3.95-4.01 (m, 1H), $4.52(\mathrm{~s}, 2 \mathrm{H}), 7.22-7.43(\mathrm{~m}, 15 \mathrm{H}), 7.41-7.43(\mathrm{~m}, 5 \mathrm{H}) .{ }^{13} \mathrm{C} \mathrm{NMR}\left(\mathrm{CDCl}_{3}, 100 \mathrm{MHz}\right)$ $\delta(\mathrm{ppm}): 64.5,70.0,71.6,73.4,86.7,127.1-128.7,138.0,143.8$.

\section{1-O-benzyl-2- $O$-[3,7-(R), 11-(R), 15-tetramethylhexadecyl]-3-O-hydroxyl-sn-glycerol $8^{3}$}

Phytanylation. To a suspension of sodium hydride $60 \%$ in oil (2.8 g, $70.8 \mathrm{mmol}, 4$ equiv) in dry THF $(25 \mathrm{~mL})$ was added a solution of alcohol 15 (7.5 g, $17.7 \mathrm{mmol}, 1$ equiv) in dry THF (30 $\mathrm{mL})$ and after 
few min phytanyl bromide $\left(8.3 \mathrm{~g}, 23.0 \mathrm{mmol}, 1.3\right.$ equiv). The reaction mixture was stirred at $120{ }^{\circ} \mathrm{C}$ for $4 \mathrm{~h}$ with a Dean Stark apparatus (Removing of the THF). Diethylic ether and water were added and the organic phase was washed with water and brine. The combined organic phases were dried $\left(\mathrm{MgSO}_{4}\right)$ and concentrated under reduced pressure. The residue was purified by flash chromatography on silica gel (PE/Et $\left.{ }_{2} \mathrm{O}: 98: 2\right)$ to yield trityled product $(10.8 \mathrm{~g}, 86 \%)$ as a colorless oil. $\mathrm{R}_{\mathrm{f}}=0.7$ (PE/EtOAc: 90:10). $[\alpha]^{20}{ }_{\mathrm{D}}:-1.0^{\circ}\left(\mathrm{c} 1, \mathrm{CH}_{2} \mathrm{Cl}_{2}\right) .{ }^{1} \mathrm{H}$ NMR $\left(\mathrm{CDCl}_{3}, 400 \mathrm{MHz}\right) \delta(\mathrm{ppm}): 0.83-0.87(\mathrm{~m}, 15 \mathrm{H}), 1.05-1.65(\mathrm{~m}$, 24H), 3.21-3.22 (d, $J=4.1 \mathrm{~Hz}, 2 \mathrm{H}), 3.51-3.64$ (m, 5H), 4.48-4.55 (m, 2H), 7.19-7.30 (m, 15H), 7.44$7.46(\mathrm{~m}, 5 \mathrm{H}) .{ }^{13} \mathrm{C} \mathrm{NMR}\left(\mathrm{CDCl}_{3}, 100 \mathrm{MHz}\right) \delta(\mathrm{ppm}): 19.71,19.77,19.84,22.72-22.82,24.49,24.59$, 24.89, 28.06, 29.88, 29.91, 32.86, 32.88, 32.90, 37.21, 37.29, 37.37, 37.49, 37.55, 37.59, 37.64, 39.45, $63.55,69.04,70.55,73.33,78.41,86.60,126.97,127.51,127.60,127.81,128.35,128.81,138.50$, 144.18. IR (neat) $v\left(\mathrm{~cm}^{-1}\right): 745,898,1098,1365,1377,1448,1490,1597,2867,2925,3031$. HRMS (ESI+): calcd for $\mathrm{C}_{49} \mathrm{H}_{68} \mathrm{O}_{3}(\mathrm{M}+\mathrm{Na})^{+}$727.5066, found: 727.5066 .

Detritylation. A mixture of trityled product (4.9 g, $7 \mathrm{mmol}, 1$ equiv) and hexahydrate iron trichloride (3.8 g, $14 \mathrm{mmol}, 2$ equiv) in dichloromethane $(60 \mathrm{~mL})$ was stirred for $2 \mathrm{~h}$ at reflux. Water and dichloromethane were added and the aqueous phase was extracted with dichloromethane. The combined organic phases were washed with aqueous $\mathrm{NaCl}$ until complete decoloration, dried $\left(\mathrm{MgSO}_{4}\right)$ and concentrated under reduced pressure. The residue was purified by flash chromatography on silica gel (PE/EtOAc: $95: 5$, 90:10 then $85: 15)$ to yield $8(1.65 \mathrm{~g}, 51 \%)$ as a colorless oil. $\mathrm{R}_{\mathrm{f}}=0.4$ (PE/EtOAc: 9:1). $[\alpha]^{20}{ }_{\mathrm{D}}=-11^{\circ}\left(c, 1, \mathrm{CH}_{2} \mathrm{Cl}_{2}\right) .{ }^{1} \mathrm{H} \mathrm{NMR}\left(\mathrm{CDCl}_{3}, 400 \mathrm{MHz}\right) \delta(\mathrm{ppm}): 0.86-0.90(\mathrm{~m}, 15 \mathrm{H}), 1.08-1.63$ (m, 24H), 2.09-2.13 (t, $J=6.0 \mathrm{~Hz}, 1 \mathrm{H}), 3.55-3.62(\mathrm{~m}, 4 \mathrm{H}), 3.63-3.70(\mathrm{~m}, 2 \mathrm{H}), 3.74-3.79(\mathrm{~m}, 1 \mathrm{H}), 4.57$ (s, 2H), 7.28-7.39 (m, 5H). ${ }^{13} \mathrm{C} \mathrm{NMR}\left(\mathrm{CDCl}_{3}, 100 \mathrm{MHz}\right) \delta(\mathrm{ppm}): 19.59,19.75,22.62,22.72,24.36$, 24.46, 24.48, 24.80, 27.97, 29.81, 32.77, 32.79, 37.05, 37.14, 37.28, 37.38, 37.40, 37.44, 37.49, 39.36, $62.88,68.67,69.99,73.51,78.42,127.63,127.80,127.71,128.41,128.72,136.47,137.97$. IR (neat) $v \mathrm{~cm}^{-1}: 733,814,1097,1366,1377,1462,1495,1725,2867,2925,3030,3425$. HRMS (ESI+): calcd for $\mathrm{C}_{30} \mathrm{H}_{54} \mathrm{O}_{3}(\mathrm{M}+\mathrm{Na})^{+}$485.3970, found: 485.3965. Anal. Calcd for $\mathrm{C}_{30} \mathrm{H}_{54} \mathrm{O}_{3}$ : C, 77.87; H, 11.76. Found: C, 77.54; H, 11.91 .

(1) Duclos, R. I. Chem. Phys. Lipids 1993, 66, 161-170.

(2) Ashton, W. T.; Canning, L. F.; Reynolds, G. F.; Tolman, R. L.; Karkas, J. D.; Liou, R.; Davies, M. E. M.; DeWitt, C. M.; Perry, H. C.; Field, A. K. J. Med. Chem. 1985, 28, 926-933.

(3) Eguchi, T.; Arakawa, K.; Kakinuma, K.; Rapp, G.; Ghosh, S.; Nakatani, Y.; Ourisson, G. Chem. Eur. J. 2000, 6, 3351-3358. 
$\mathrm{CDCl}_{3} / \mathrm{MeOD}: 1: 1{ }^{1} \mathrm{H}$ NMR (400 MHz) and ${ }^{13} \mathrm{C}$ NMR (100 MHz) of compound 2
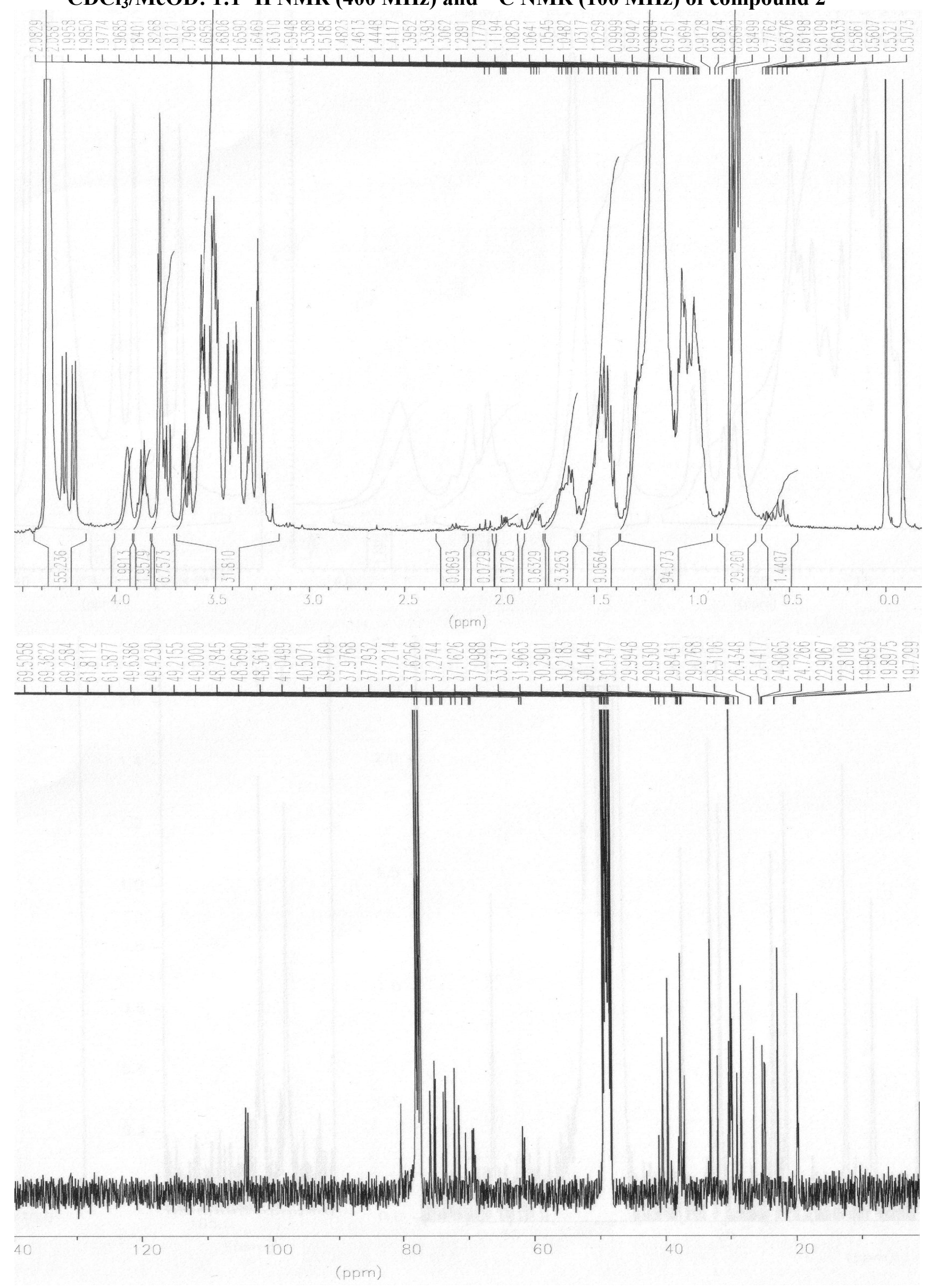
$\mathrm{CDCl}_{3} / \mathrm{MeOH}$ : 1:1 ${ }^{1} \mathrm{H}$ NMR $400 \mathrm{MHz}$ and ${ }^{13} \mathrm{C}$ NMR (100 MHz) of compound 3
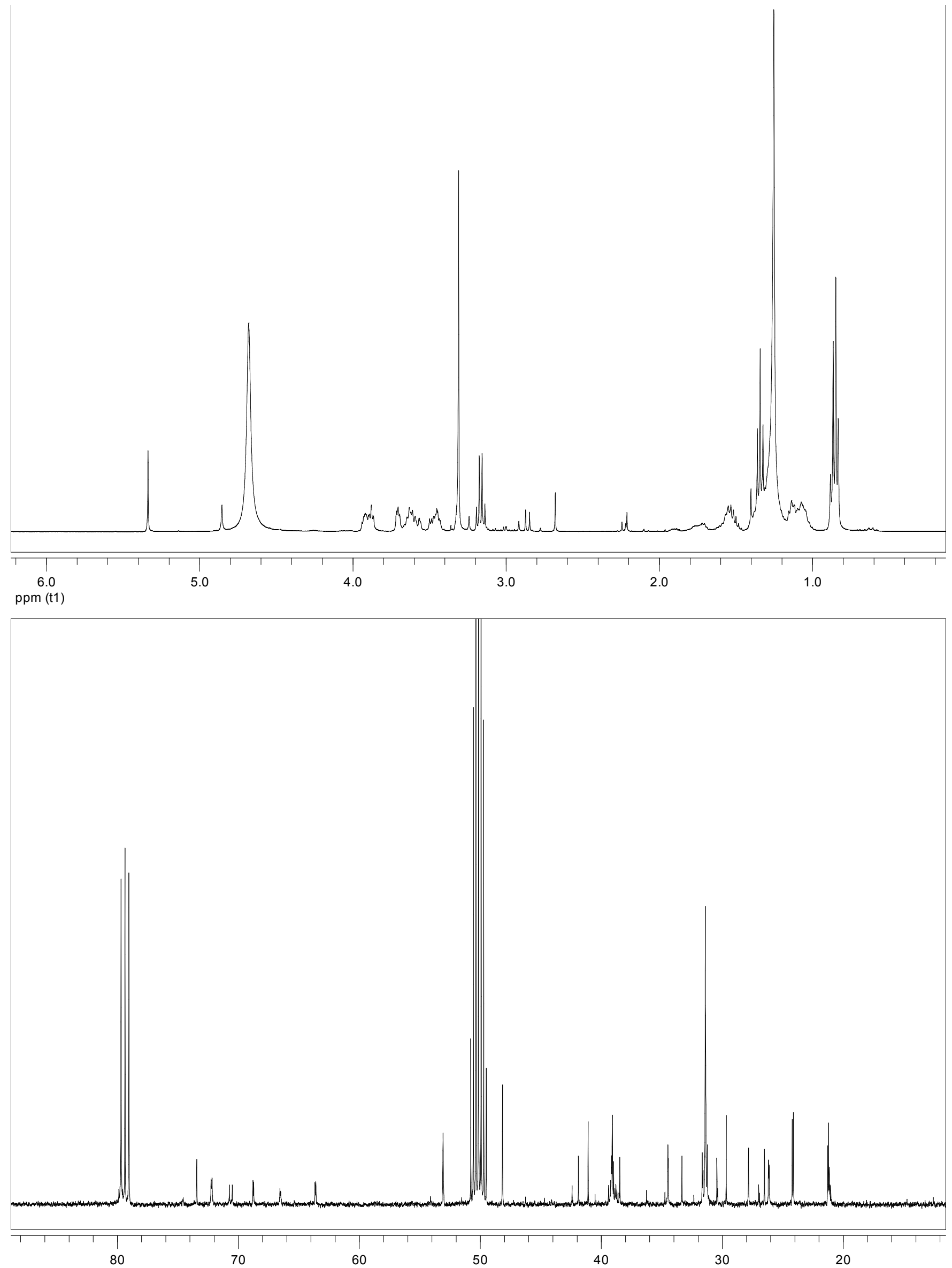

ppm (t1) 


\section{$\mathrm{CDCl}_{3}{ }^{13} \mathrm{C}$ NMR (100MHz) of compound 4}

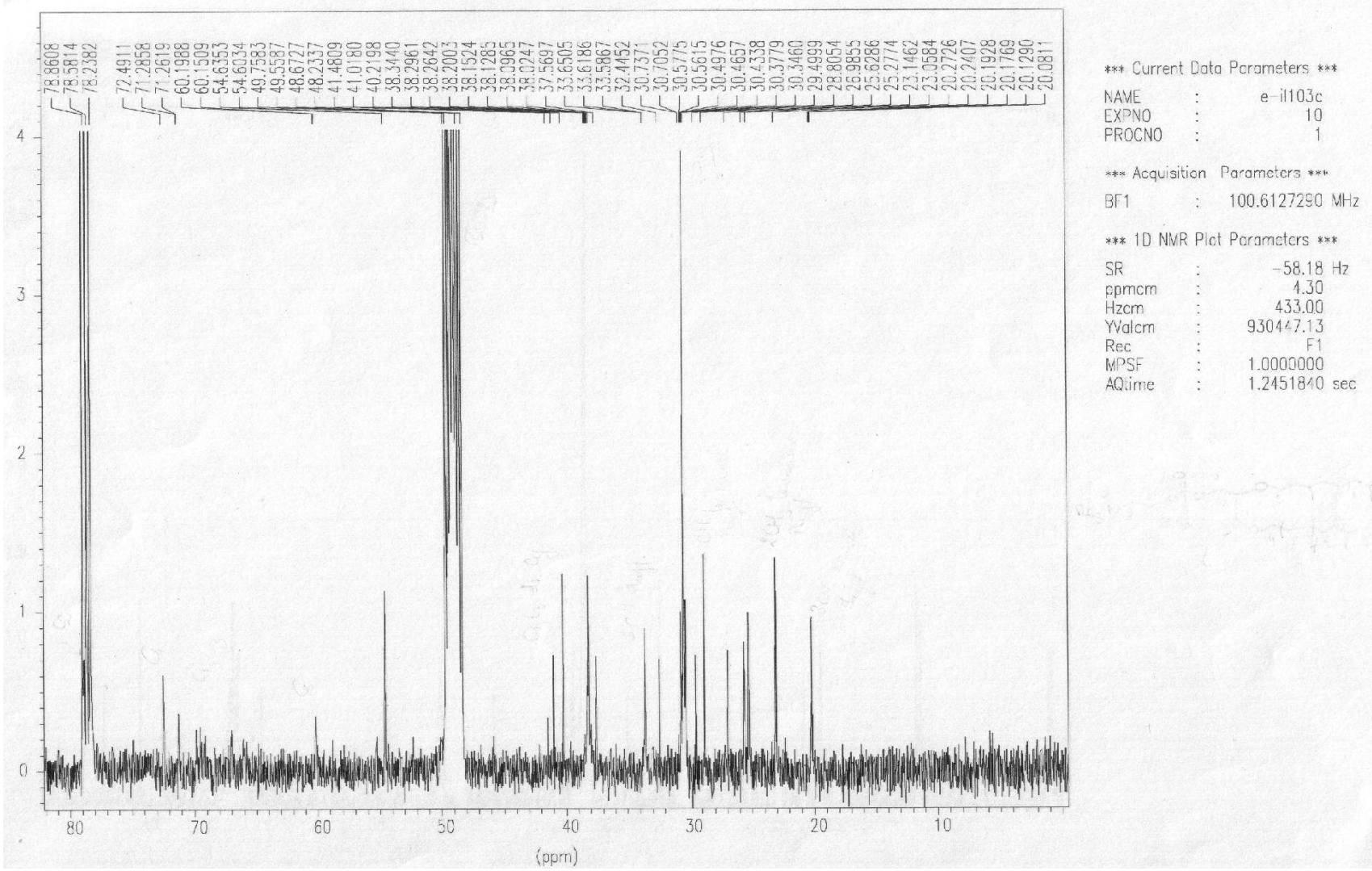

\section{$\mathrm{CDCl}_{3}{ }^{1} \mathrm{H}$ NMR (400 MHz) of compound 5a}

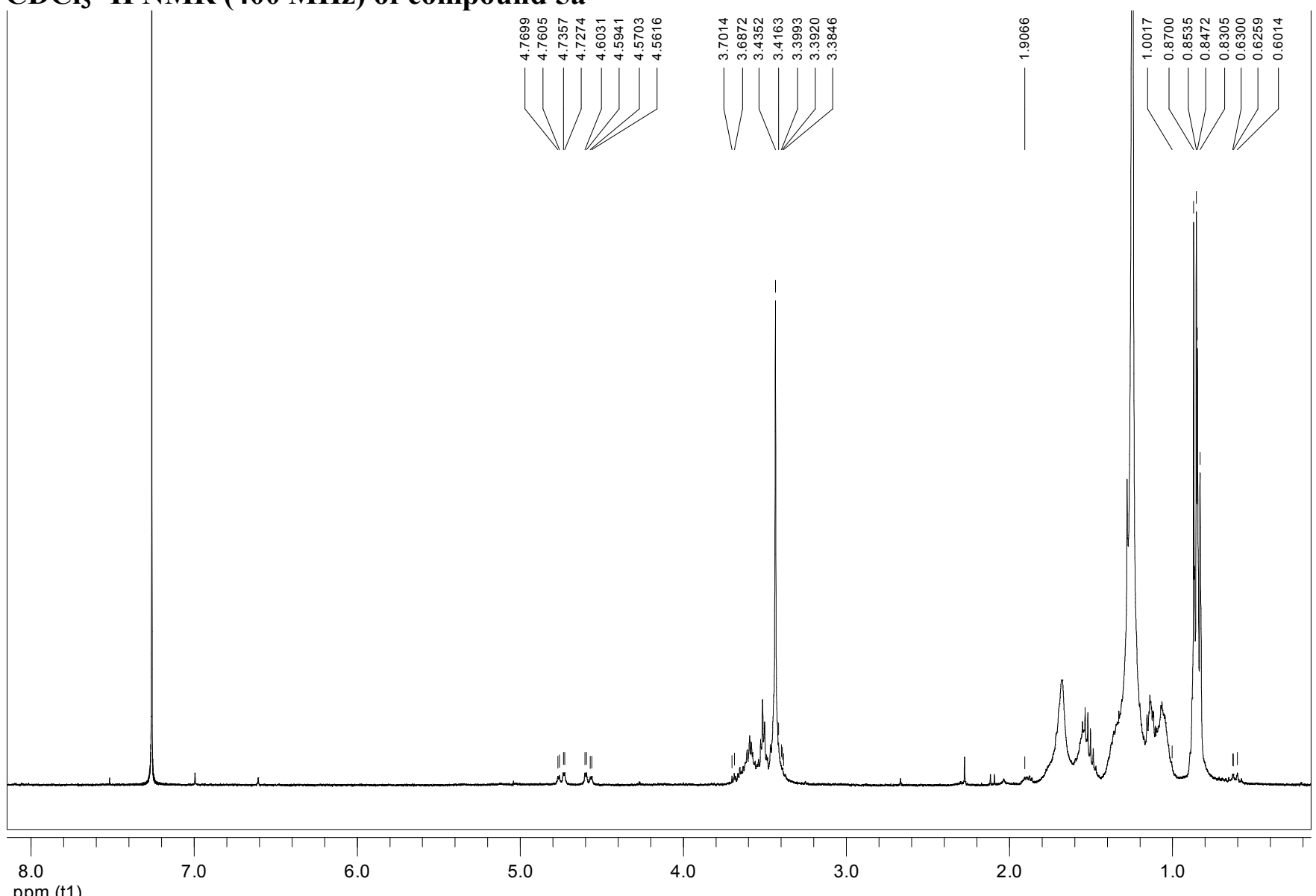


$\mathrm{CDCl}_{3}{ }^{1} \mathrm{H}$ NMR (400 MHz) and ${ }^{13} \mathrm{C}$ NMR (100MHz) of compound 5b

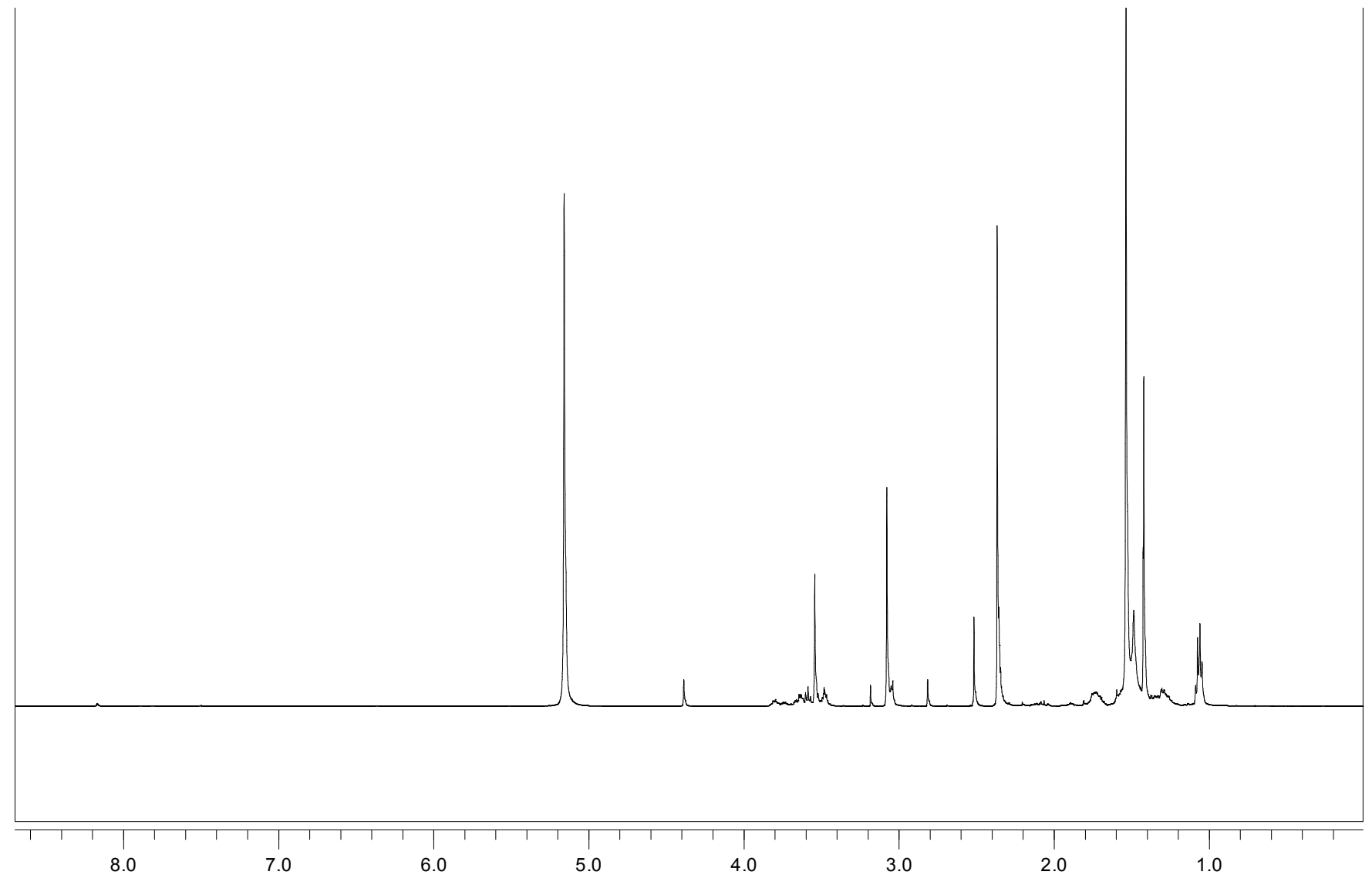

ppm (t1)

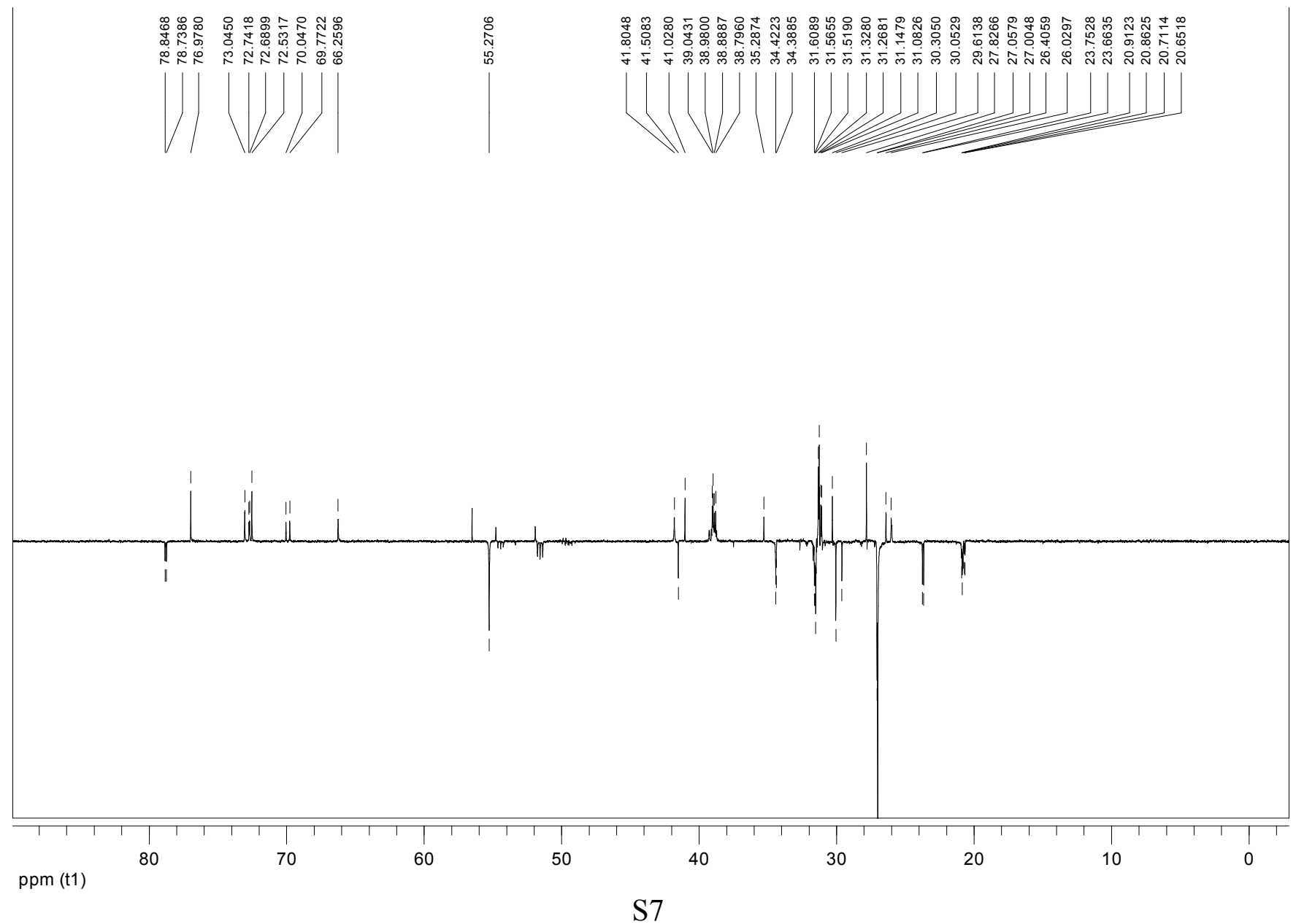


$\mathrm{CDCl}_{3}{ }^{1} \mathrm{H}$ NMR (400 MHz) and ${ }^{13} \mathrm{C}$ NMR (100MHz) of compound 6 (protected)

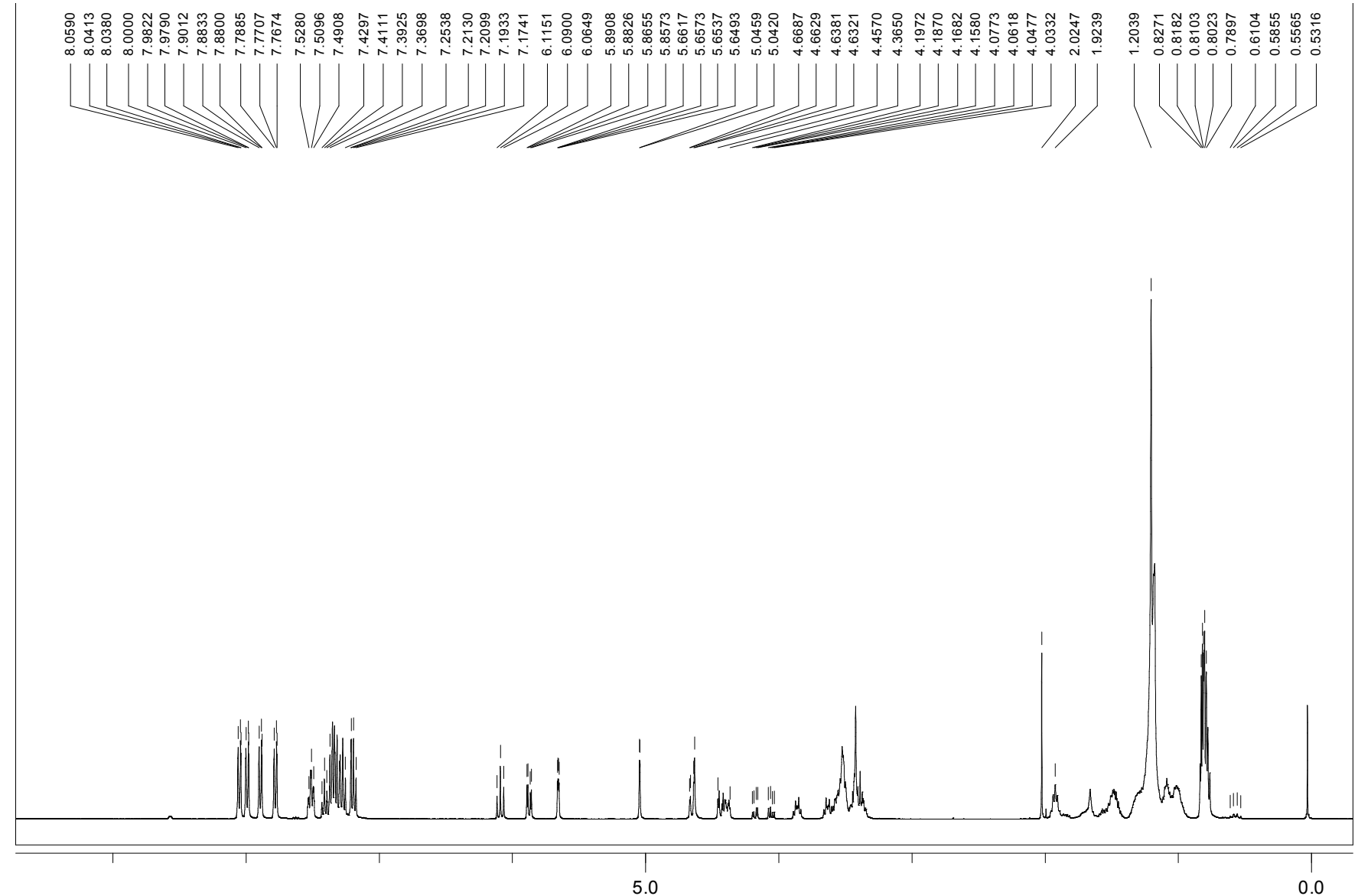

ppm (t1)

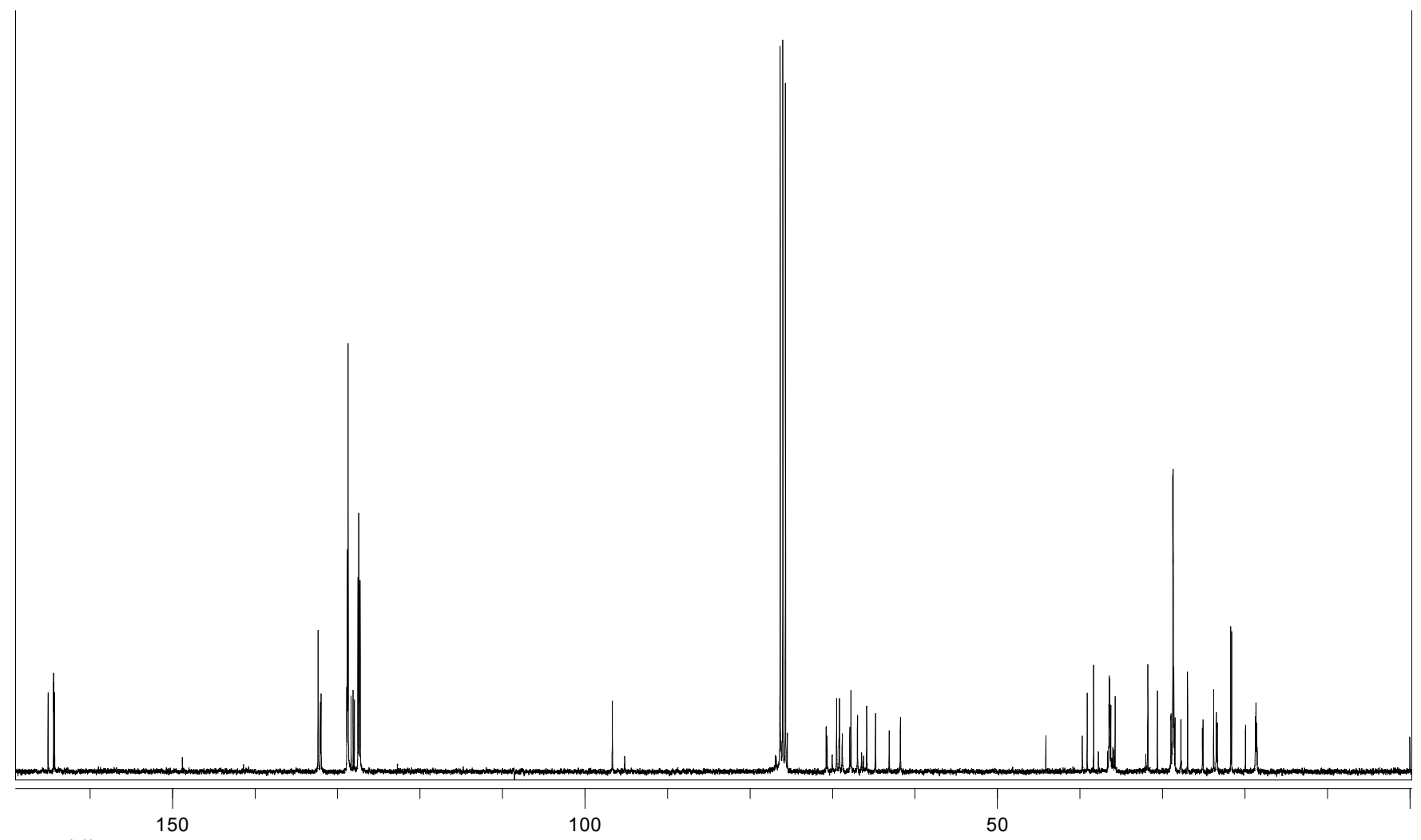

ppm (t1) 
$\mathrm{CDCl}_{3} / \mathrm{MeOD}$ : 1:1 ${ }^{1} \mathrm{H}$ NMR (400 MHz) and ${ }^{13} \mathrm{C}$ NMR (100 MHz) of compound 6

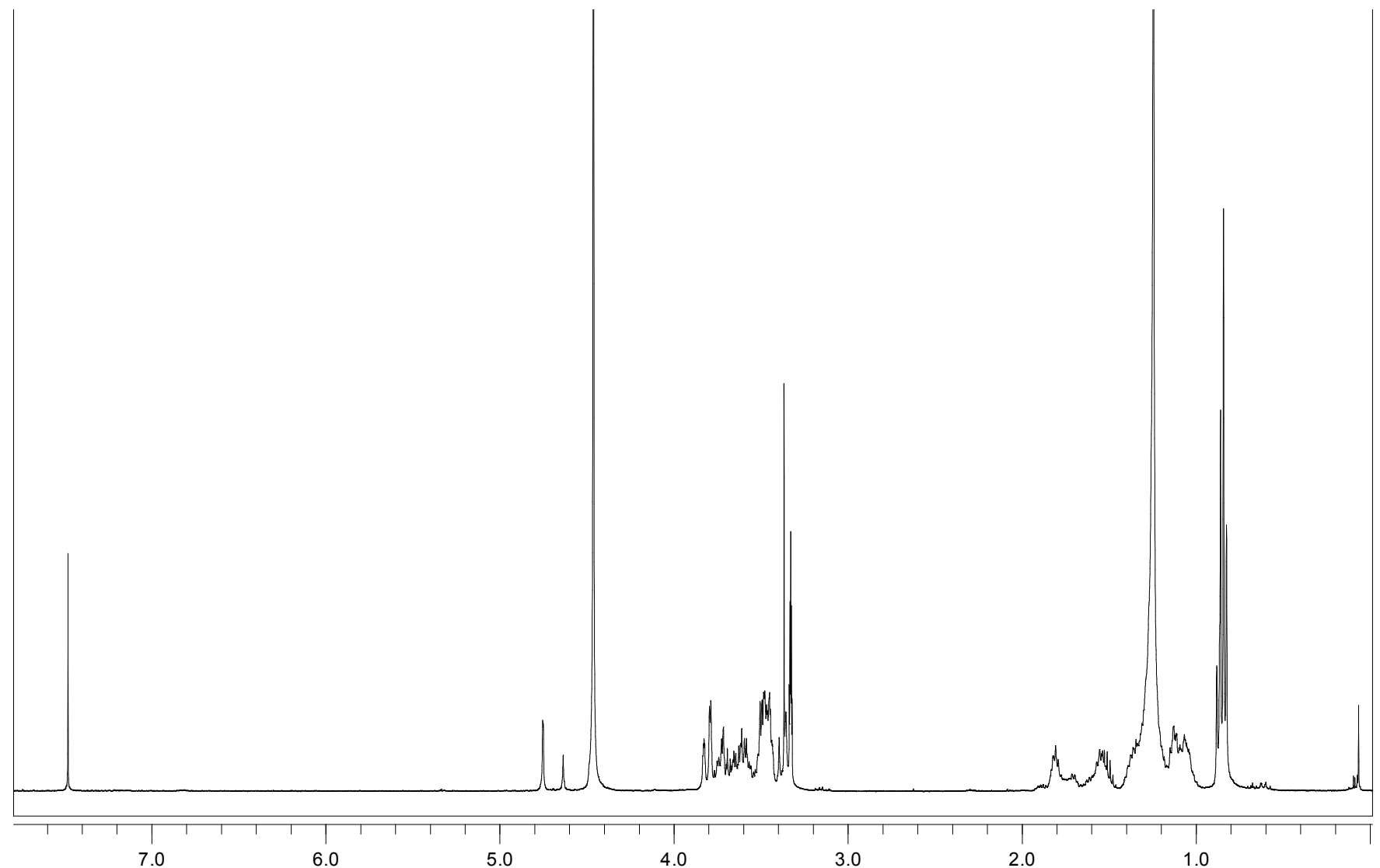

ppm (t1)

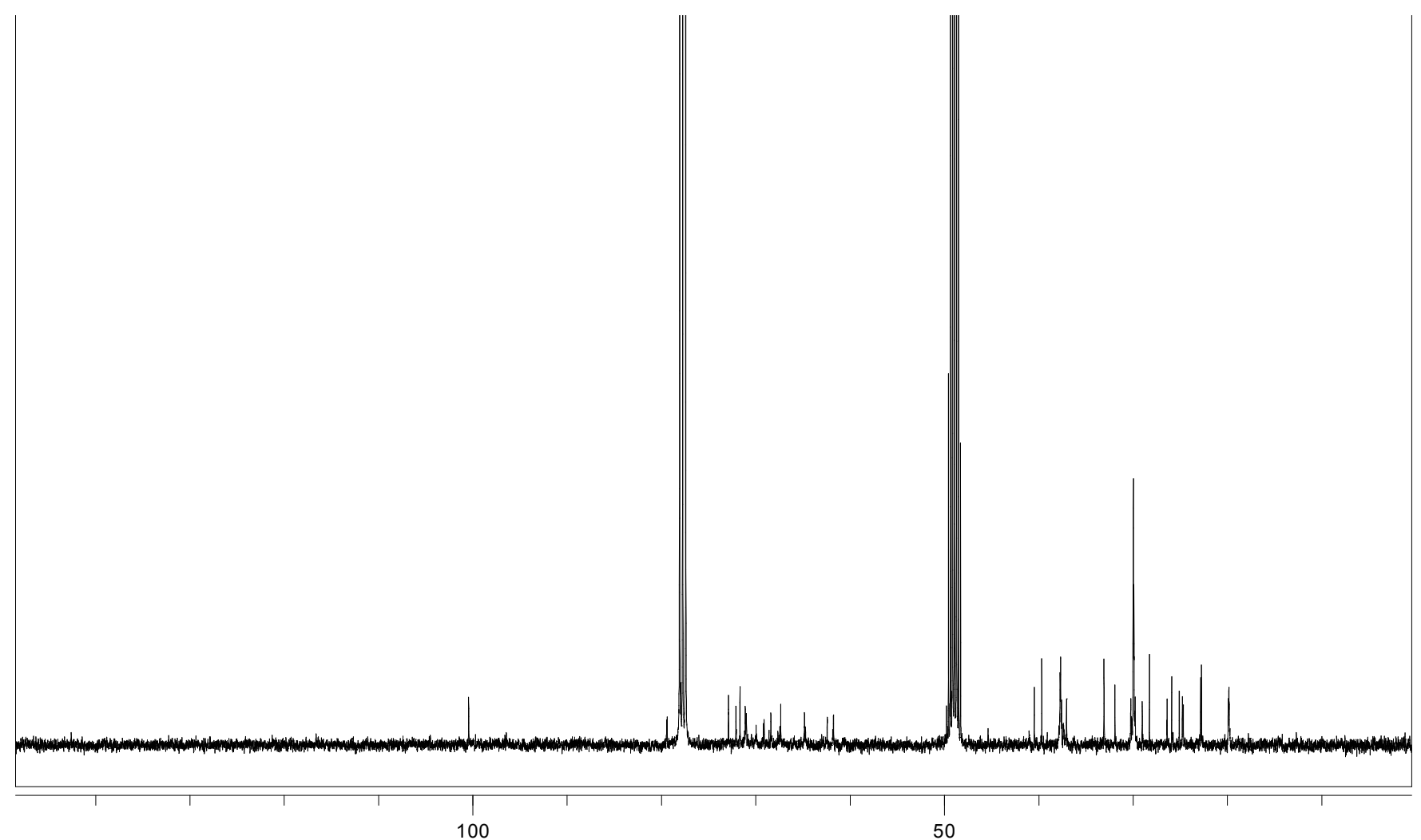

ppm (t1) 
$\mathrm{CDCl}_{3}{ }^{1} \mathrm{H}$ NMR (400 MHz) and ${ }^{13} \mathrm{C}$ NMR (100 MHz) of compound 7 (protected)

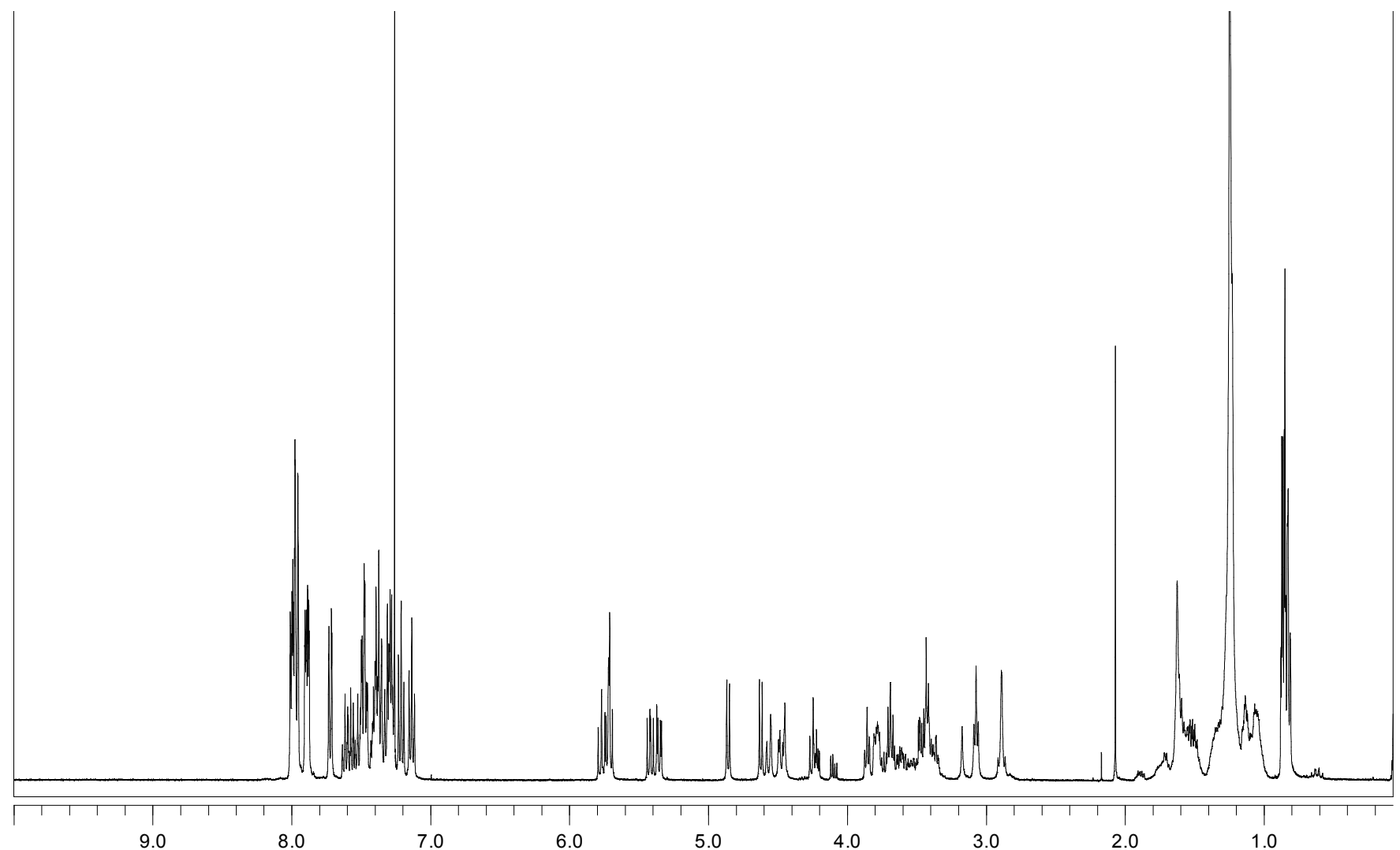

$\mathrm{ppm}(\mathrm{t} 1)$

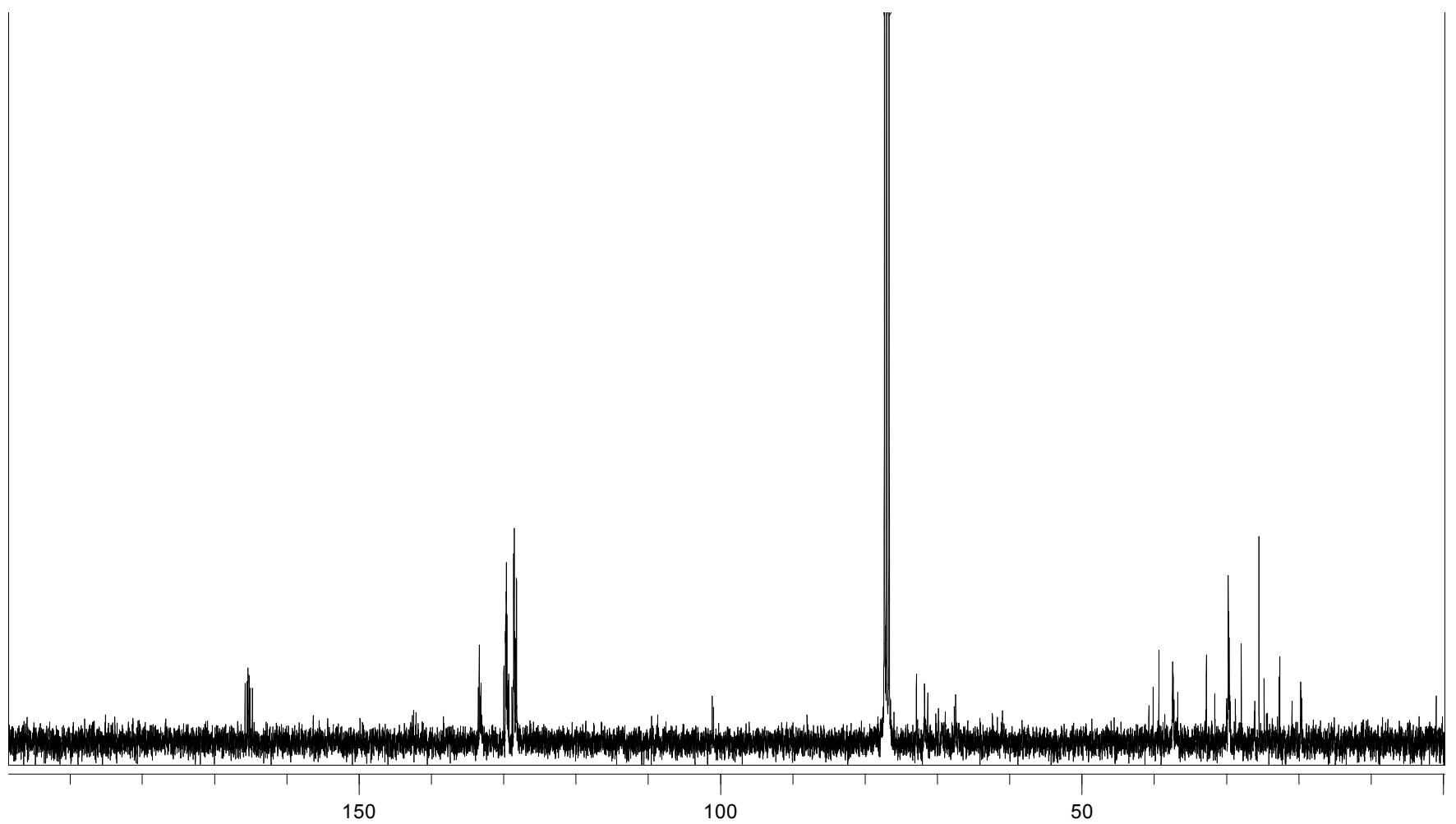

ppm (t1) 
$d_{5}$-pyridine ${ }^{1} \mathrm{H}$ NMR (400 MHz) of compound 7

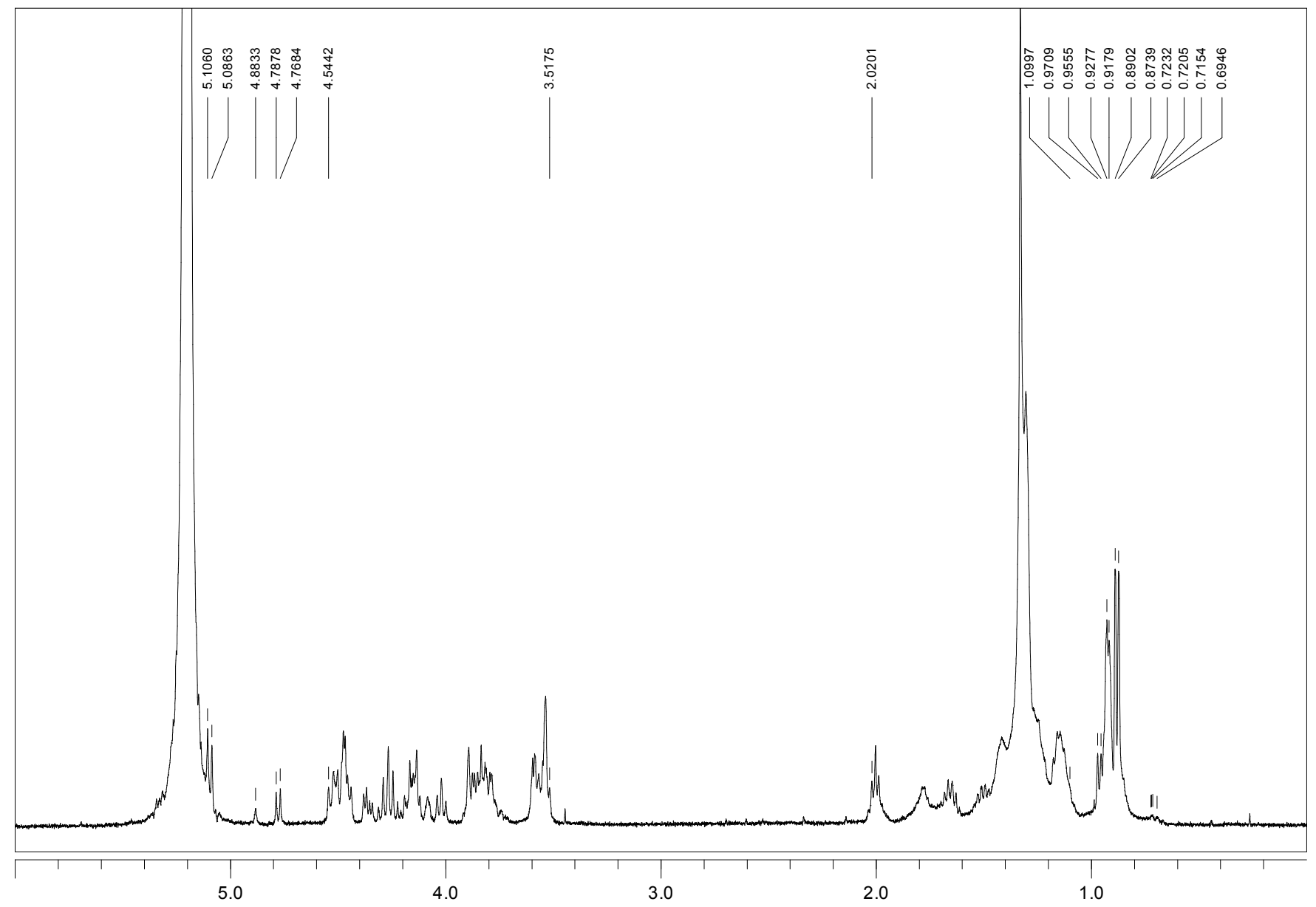

ppm (t1) 
$\mathrm{CDCl}_{3}{ }^{1} \mathrm{H}$ NMR (400 MHz) and ${ }^{13} \mathrm{C}$ NMR (100 MHz) of compound 9a
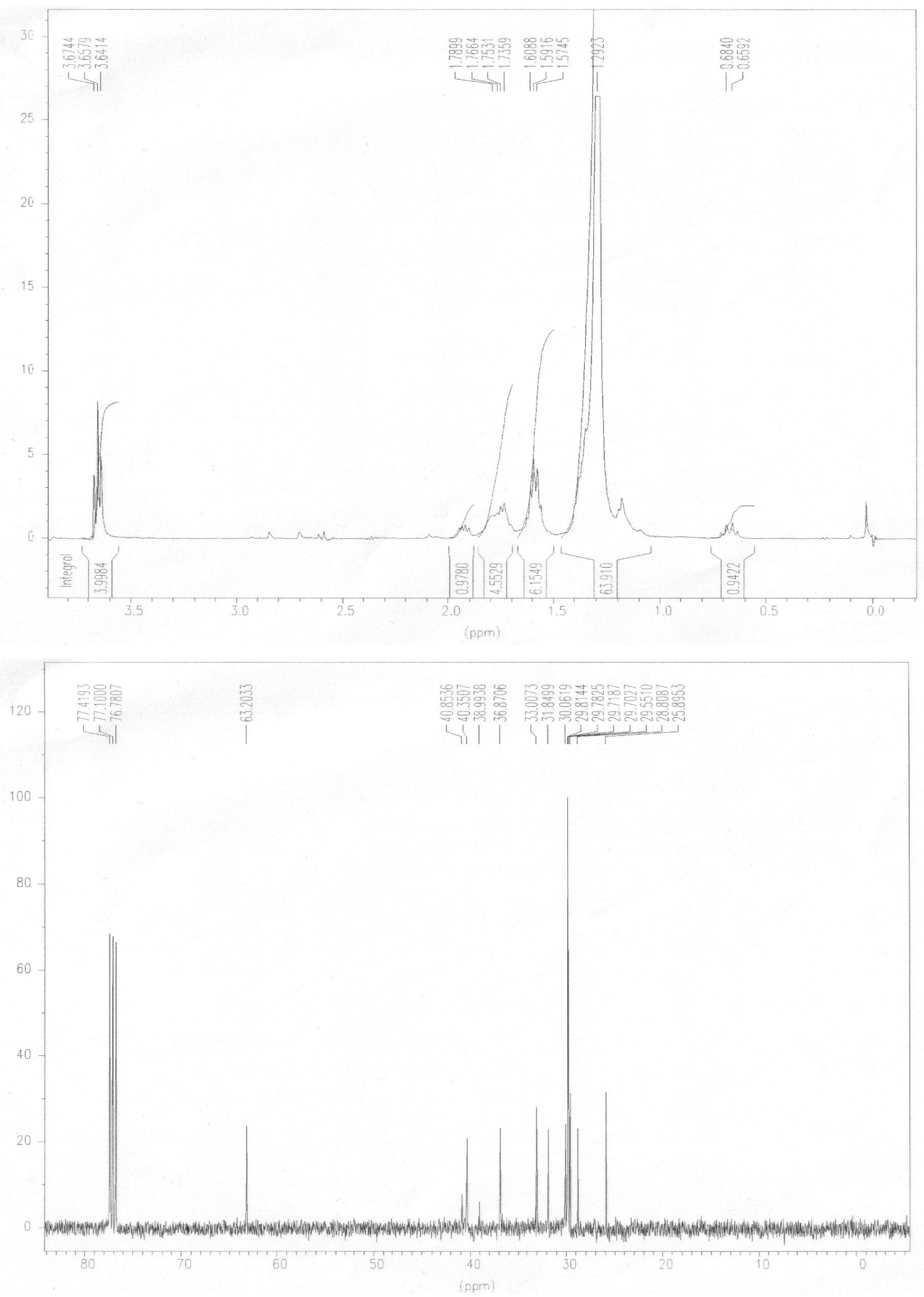
$\mathrm{CDCl}_{3}{ }^{1} \mathrm{H}$ NMR (400 MHz) and ${ }^{13} \mathrm{C}$ NMR (100 MHz) of compound 18

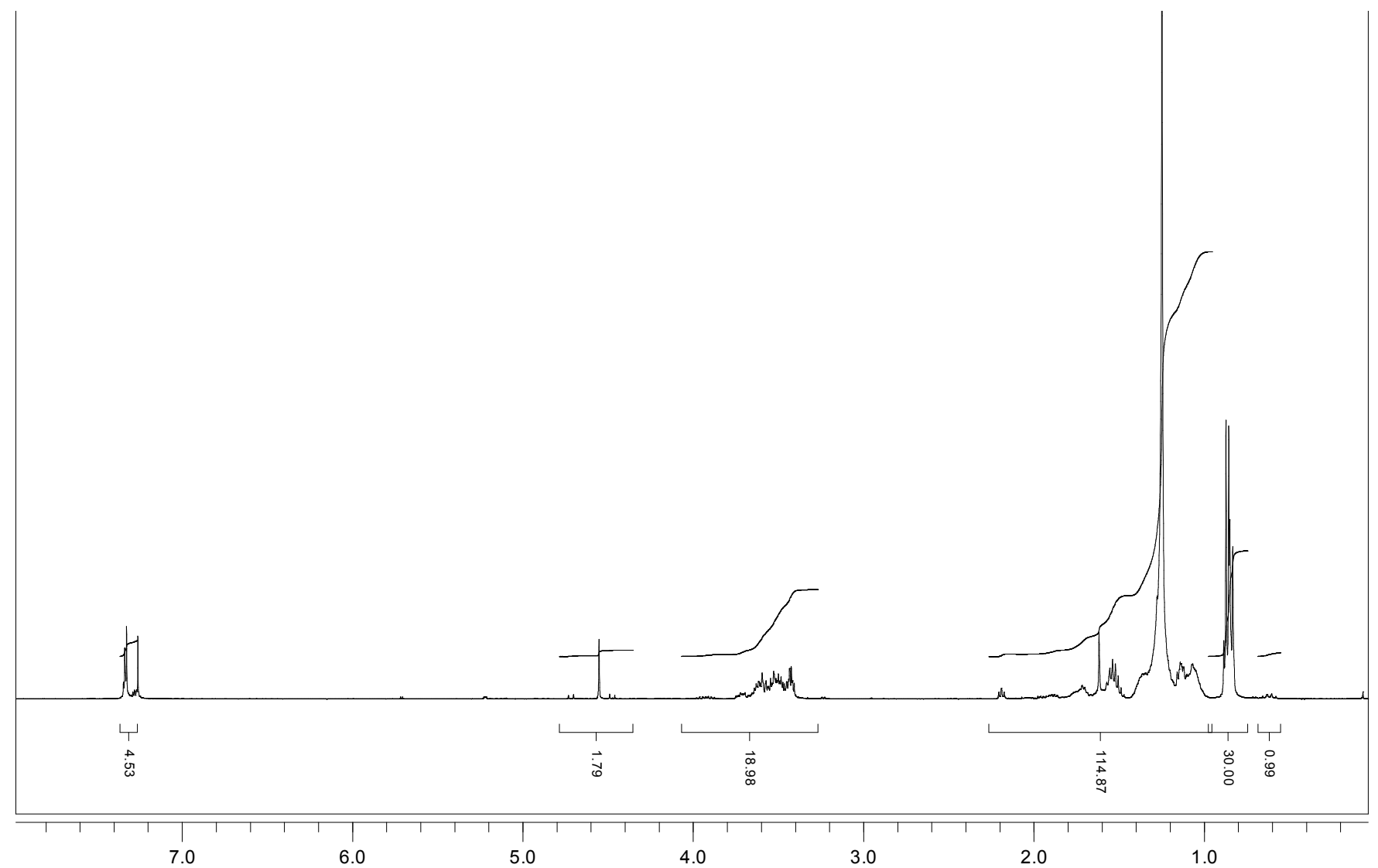

ppm (t1)

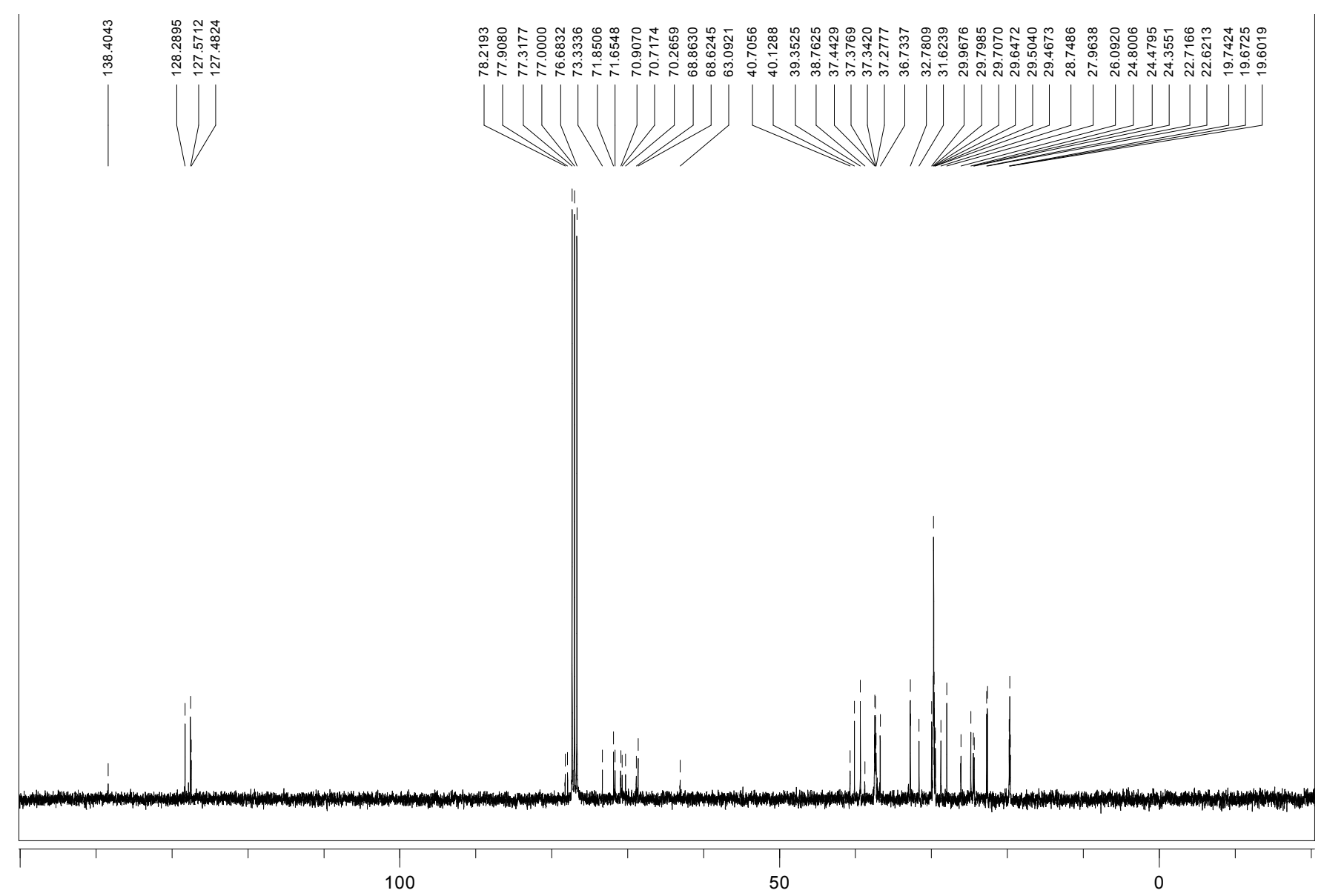

ppm (t1) 
$\mathrm{CDCl}_{3}{ }^{1} \mathrm{H}$ NMR (400 MHz) and ${ }^{13} \mathrm{C}$ NMR (100 MHz) of compound 19

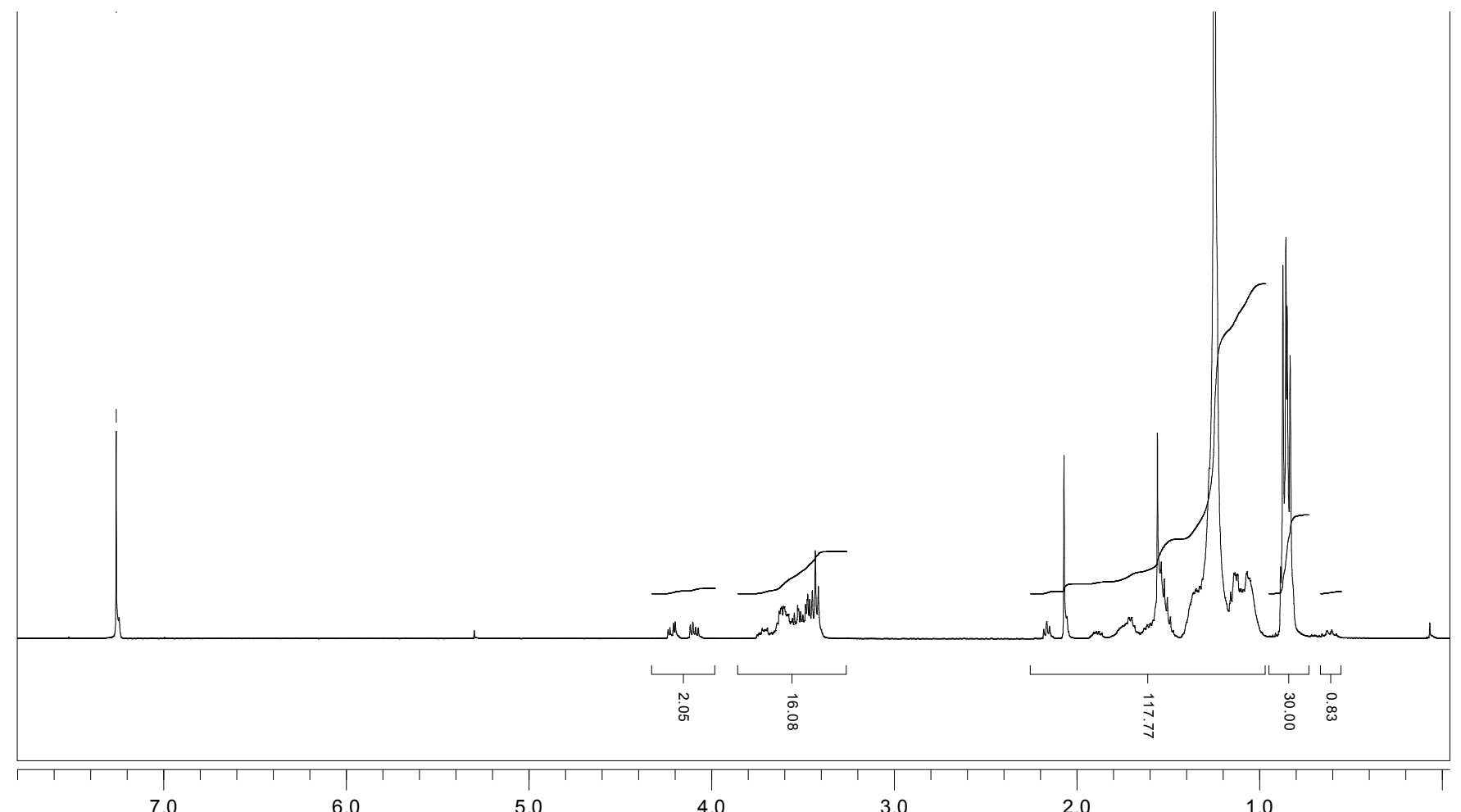

ppm (t1)

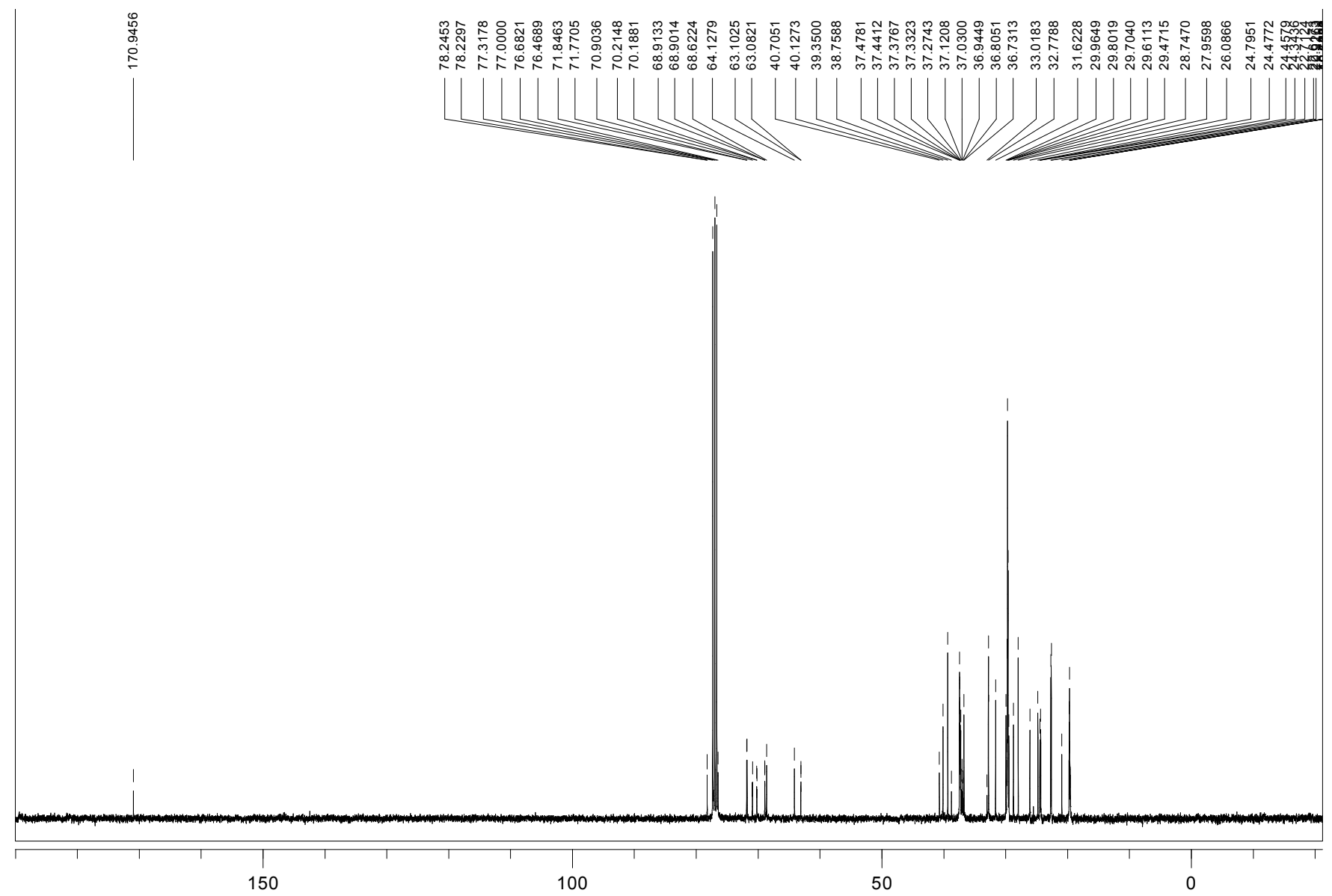

ppm (t1) 
$\mathrm{CDCl}_{3}{ }^{1} \mathrm{H}$ NMR (400 MHz) and ${ }^{13} \mathrm{C}$ NMR (100 MHz) of compound 20a

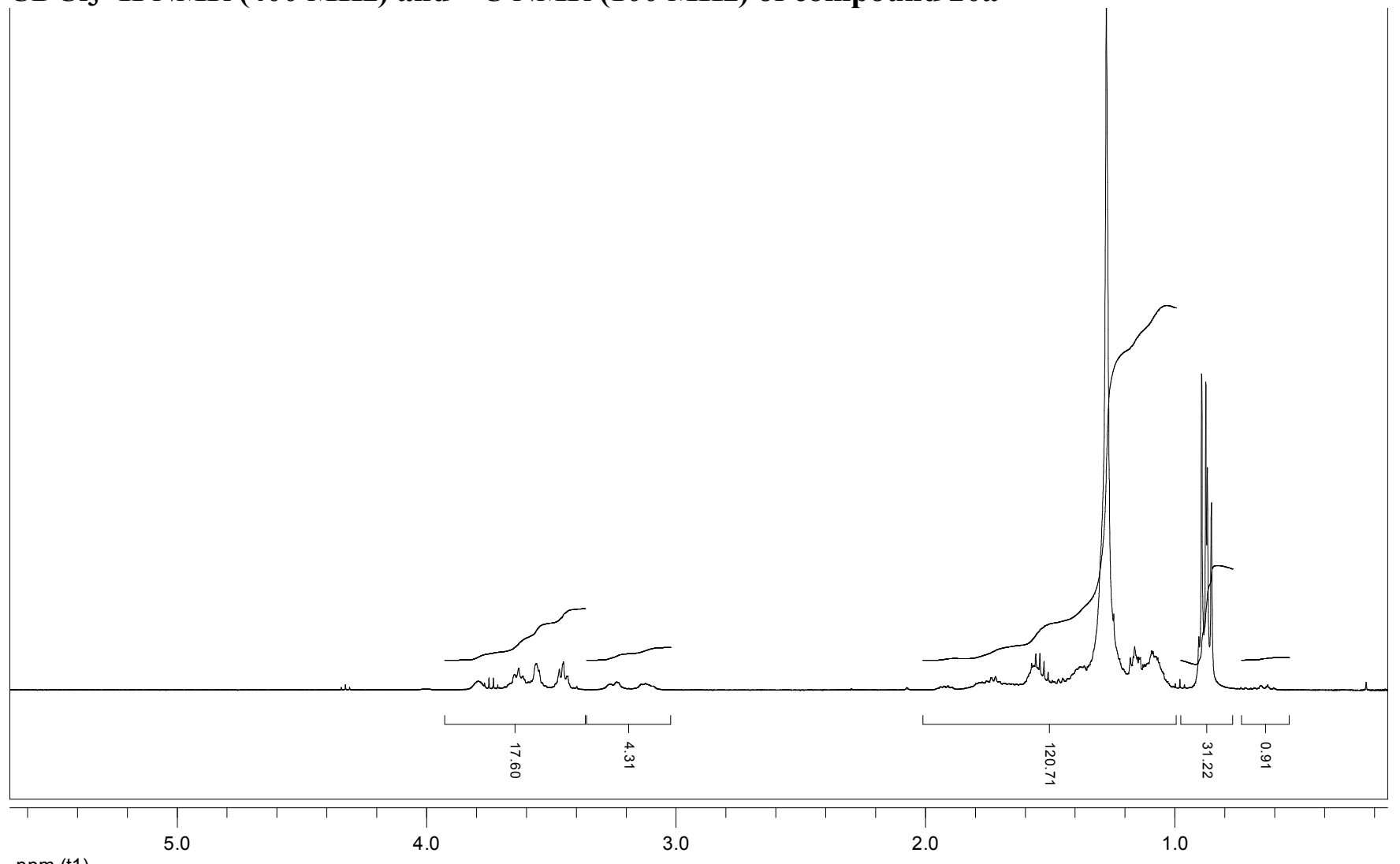

ppm (t1)

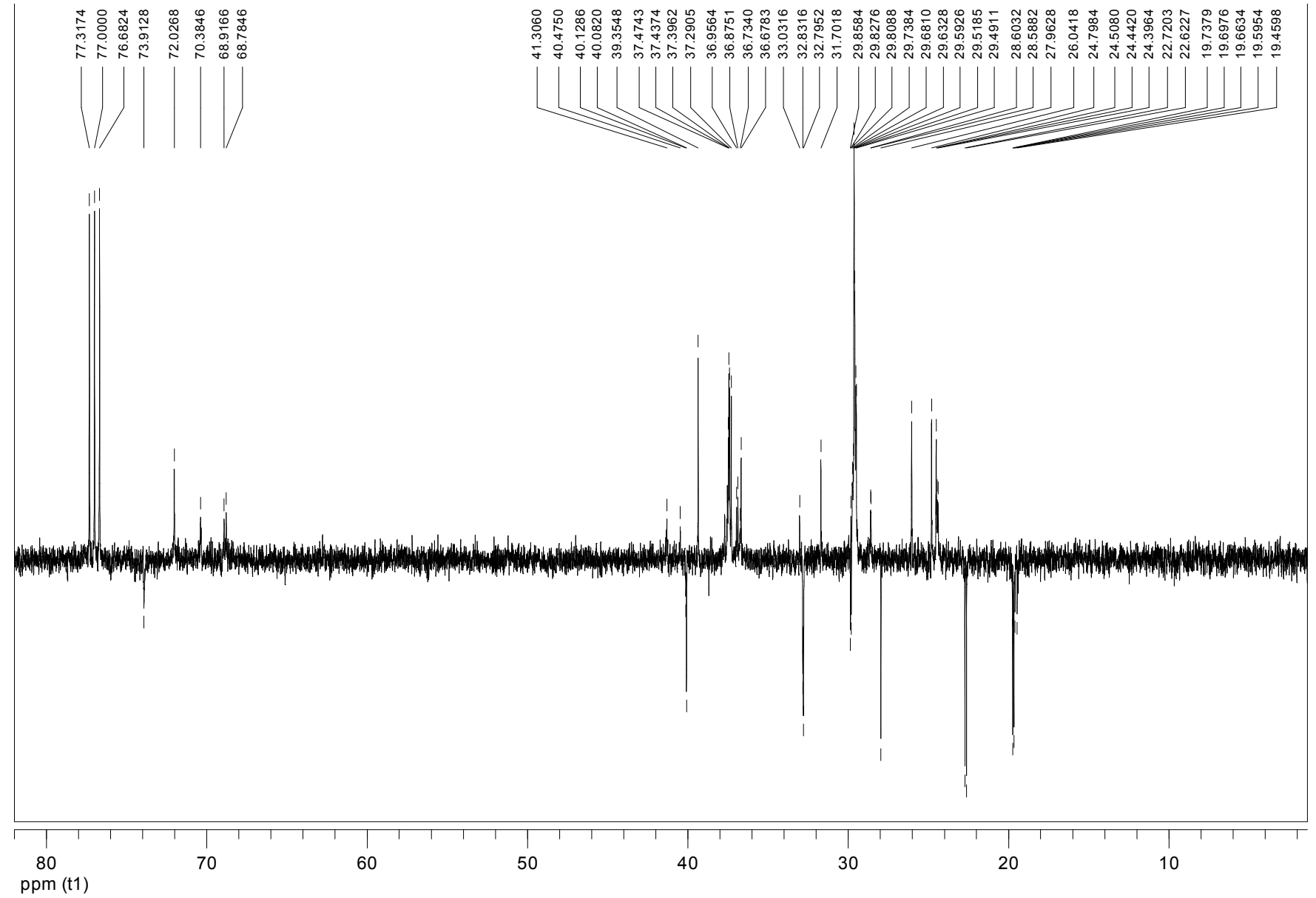


$\mathrm{CDCl}_{3}{ }^{1} \mathrm{H}$ NMR (400 MHz) and ${ }^{13} \mathrm{C}$ NMR (100 MHz) of compound 20b
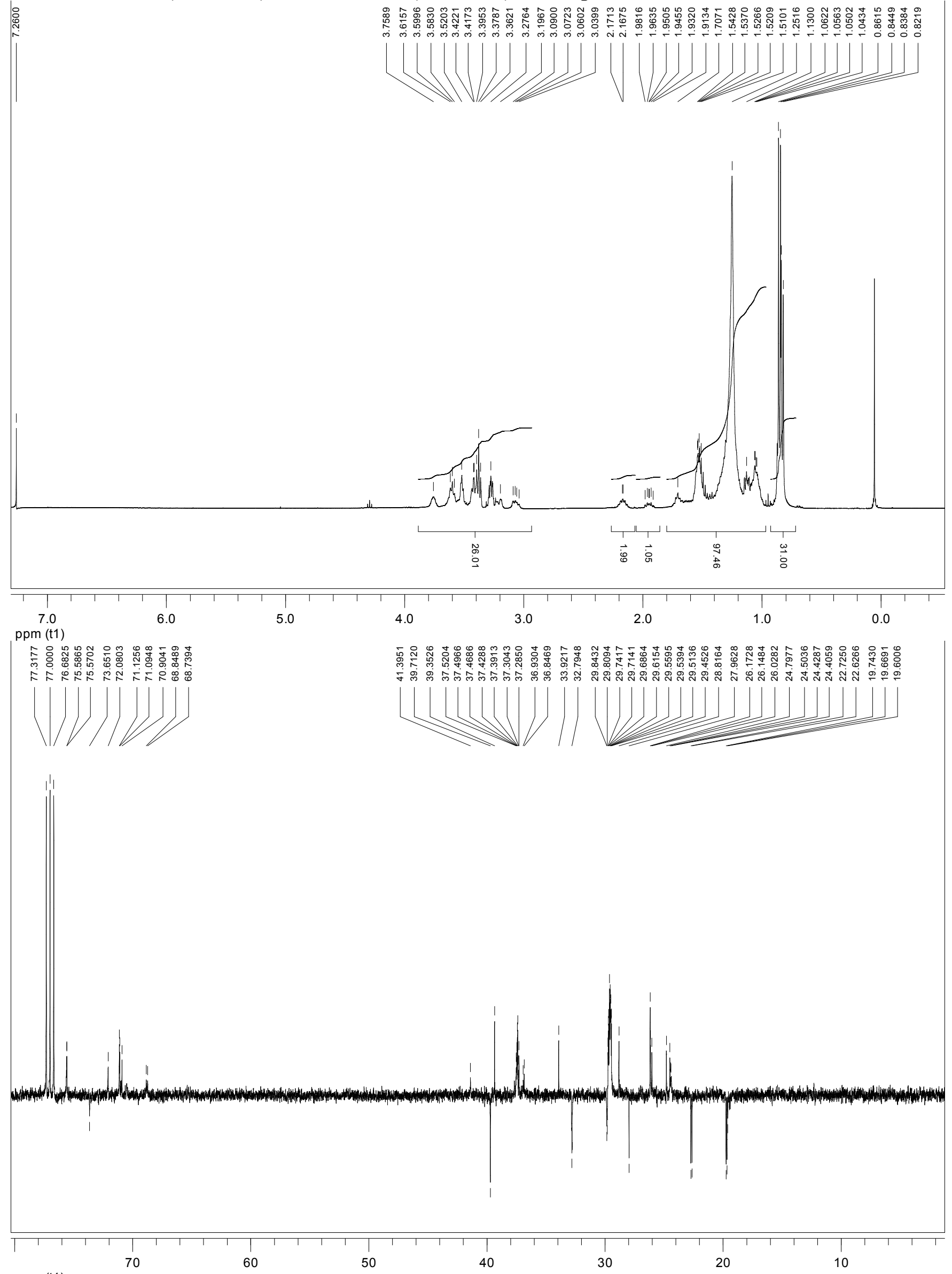

ppm (t1)

S16 
$\mathrm{CDCl}_{3}{ }^{1} \mathrm{H}$ NMR (400 MHz) and ${ }^{13} \mathrm{C}$ NMR (100 MHz) of compound 22a

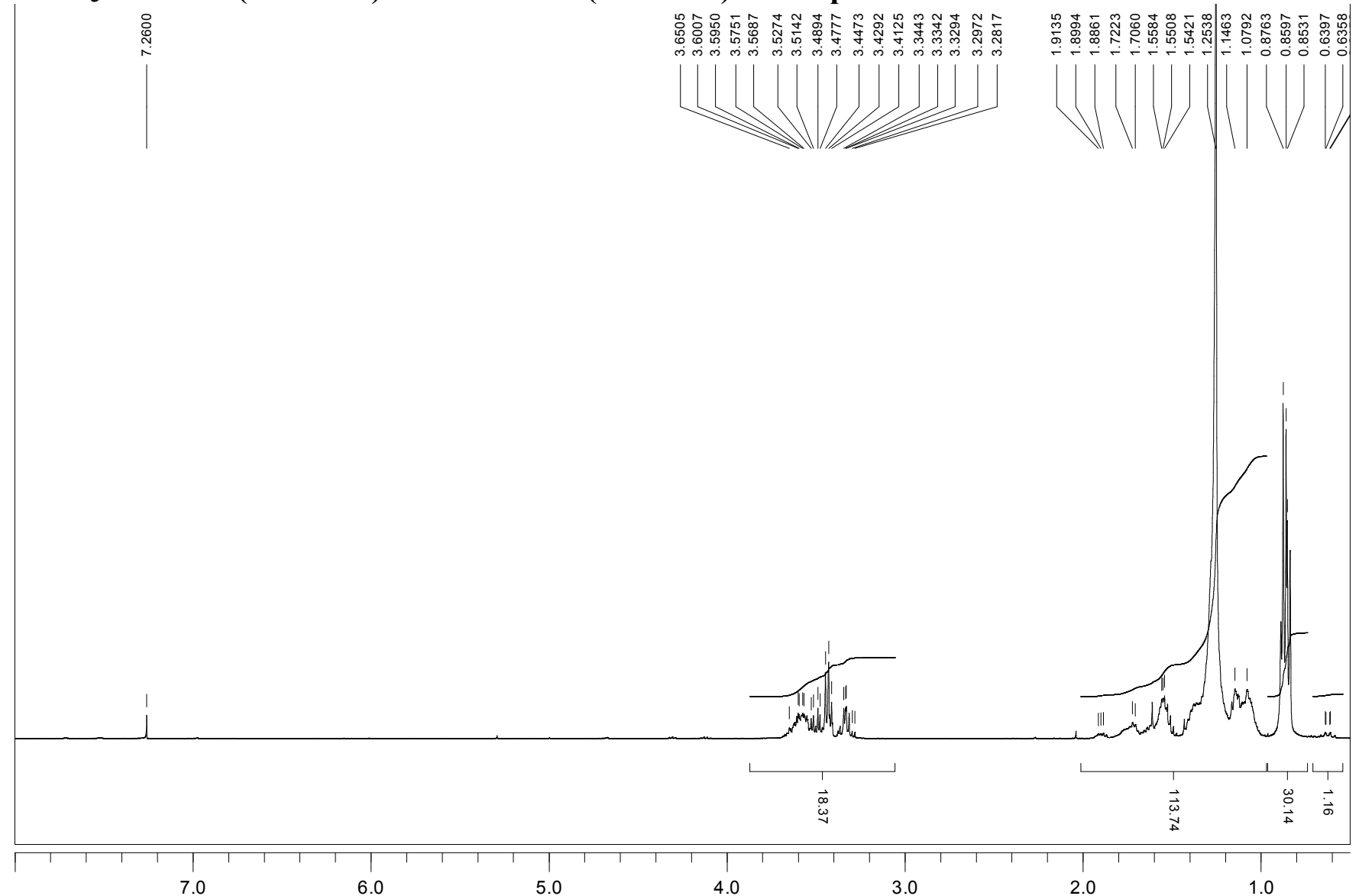

ppm (t1)

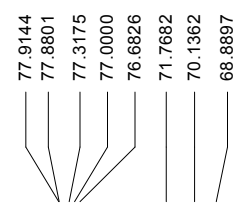

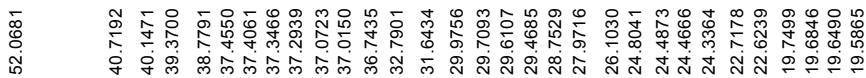

$\lfloor\lfloor\rfloor\rfloor\rfloor\rfloor\rfloor\rfloor\rfloor\rfloor\rfloor\rfloor\rfloor\rfloor\rfloor\rfloor\rfloor\rfloor\rfloor$
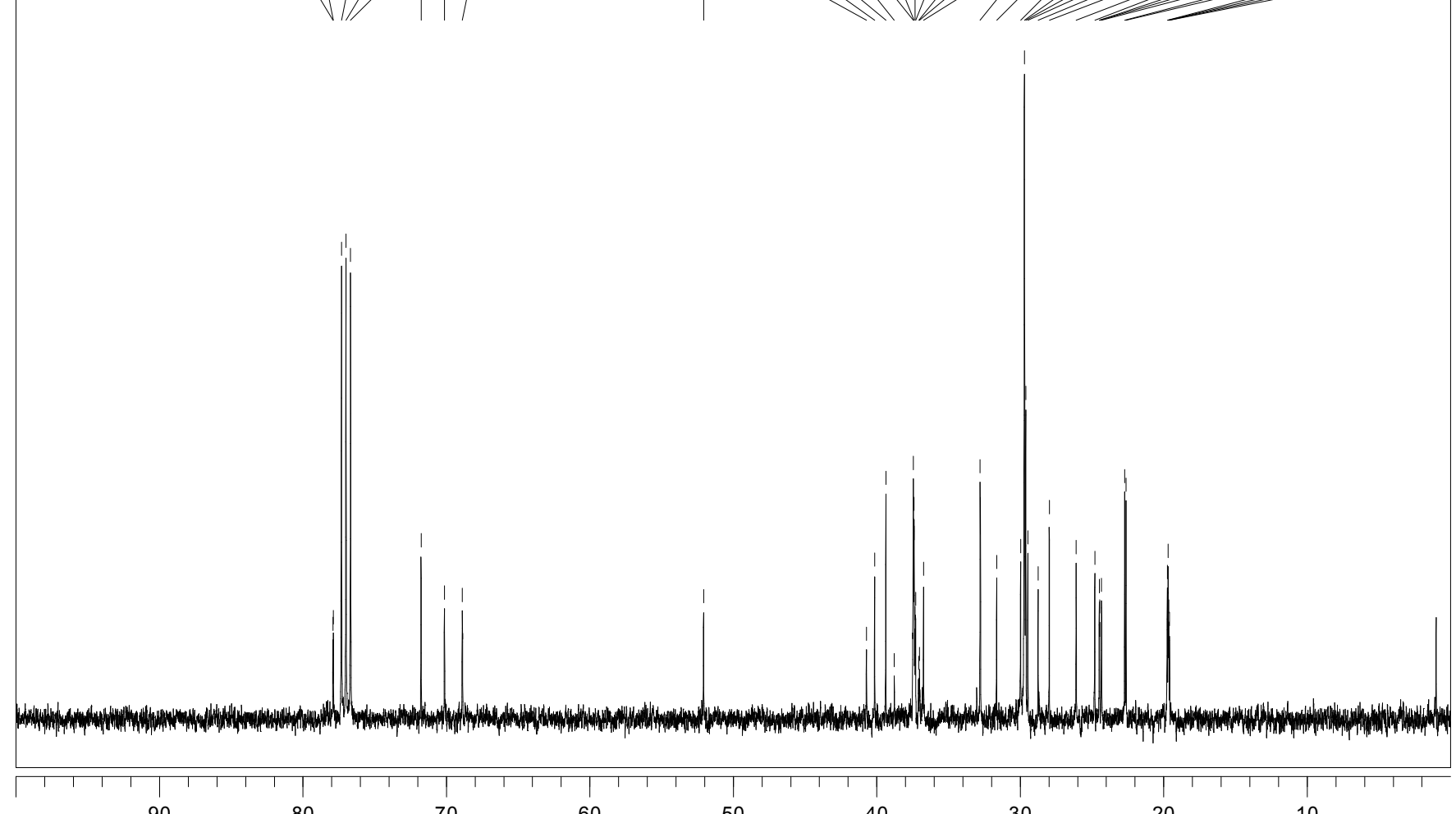

ppm (f1)

90

80

60

50

40

$\prod_{30}$

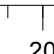


$\mathrm{CDCl}_{3}{ }^{1} \mathrm{H}$ NMR (400 MHz) and ${ }^{13} \mathrm{C}$ NMR (100 MHz) of compound 22b
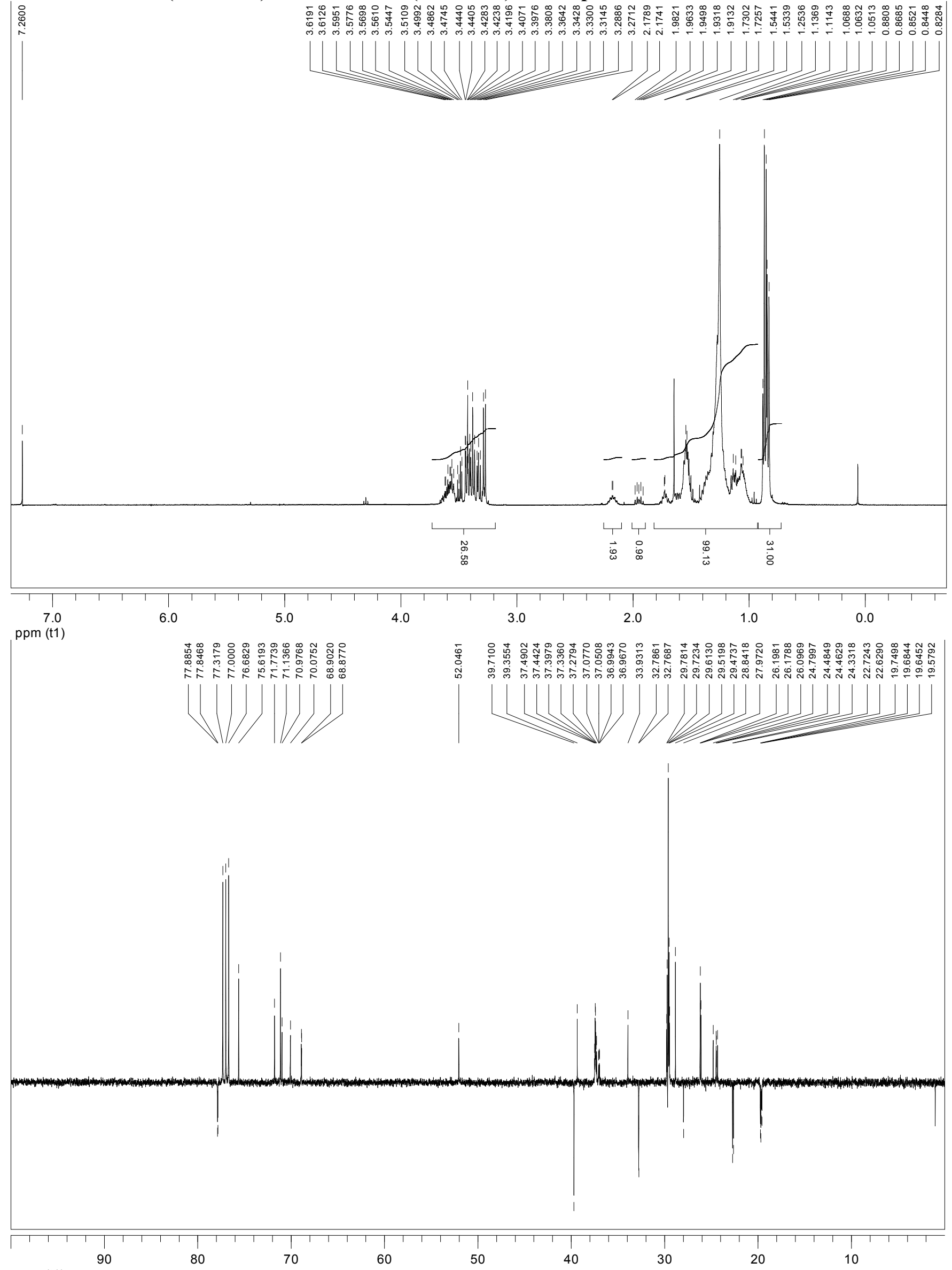

ppm (t1)

80

50 
$\mathrm{CDCl}_{3}{ }^{1} \mathrm{H}$ NMR (400 MHz) and ${ }^{13} \mathrm{C}$ NMR (100MHz) of compound 23
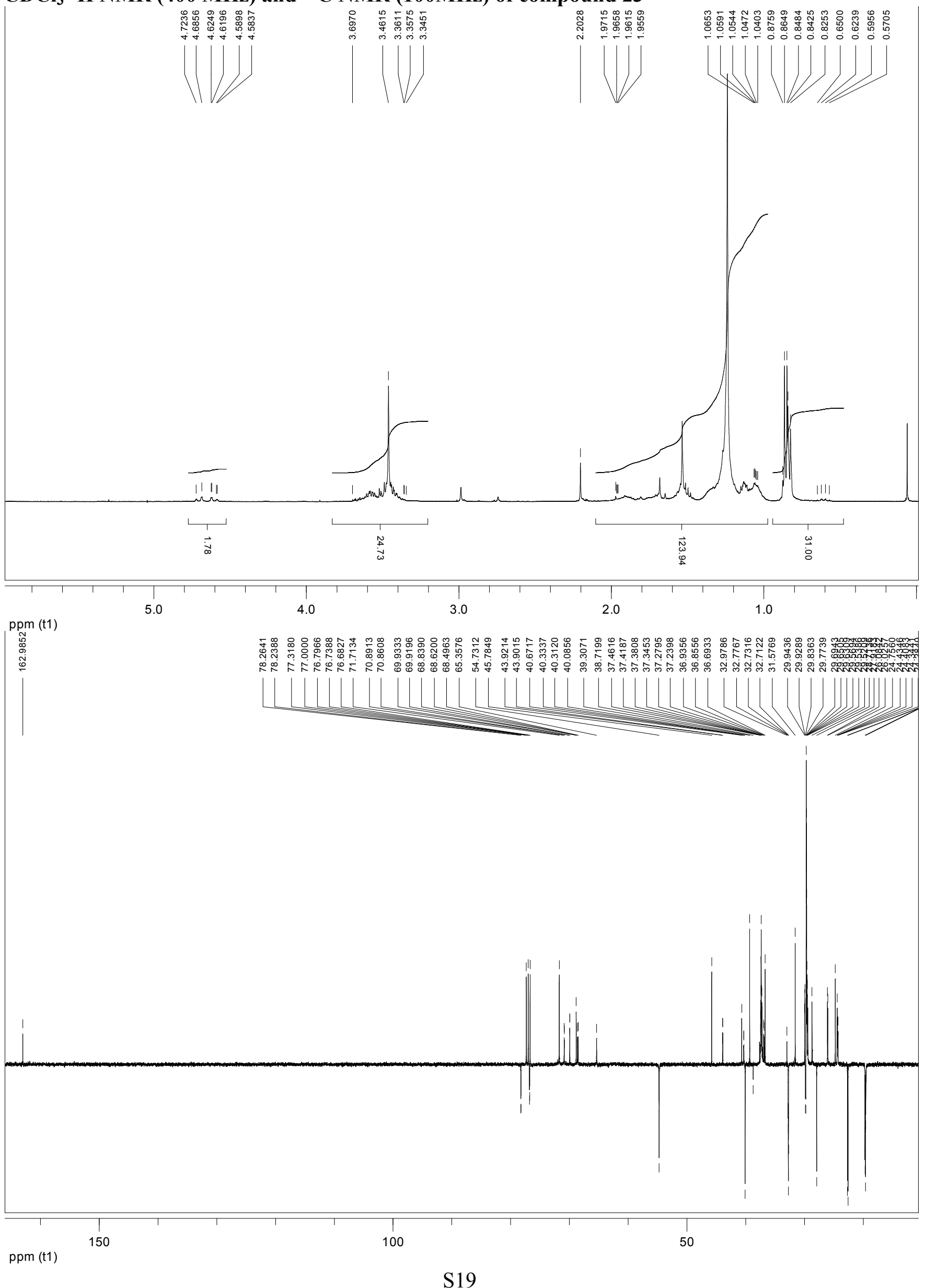
$\mathrm{CDCl}_{3}{ }^{1} \mathrm{H}$ NMR (400 MHz) and ${ }^{13} \mathrm{C}$ NMR (100MHz) of compound 25

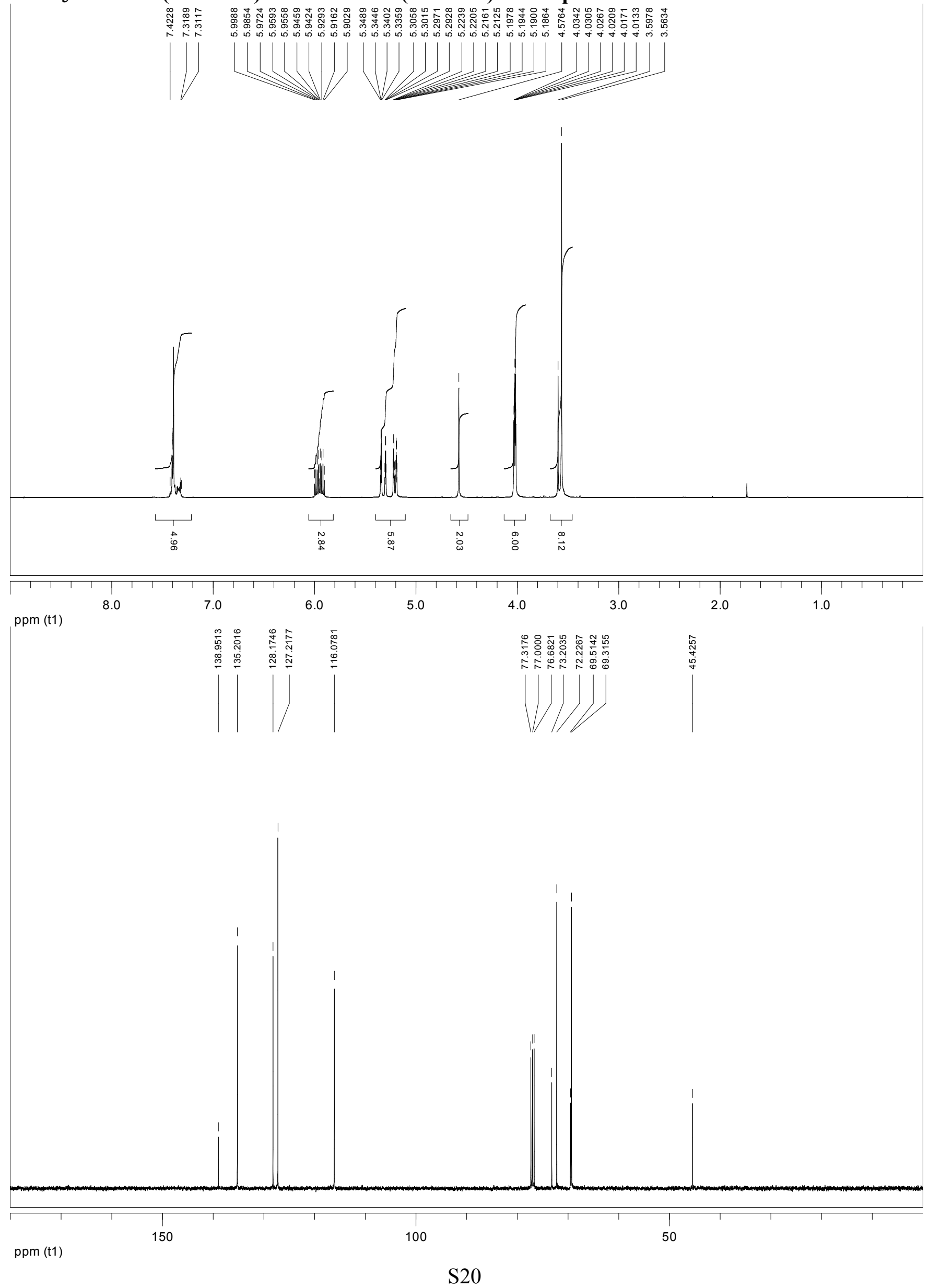


$\mathrm{CDCl}_{3}{ }^{1} \mathrm{H}$ NMR (400 MHz) and ${ }^{13} \mathrm{C}$ NMR (100MHz) of compound 28a

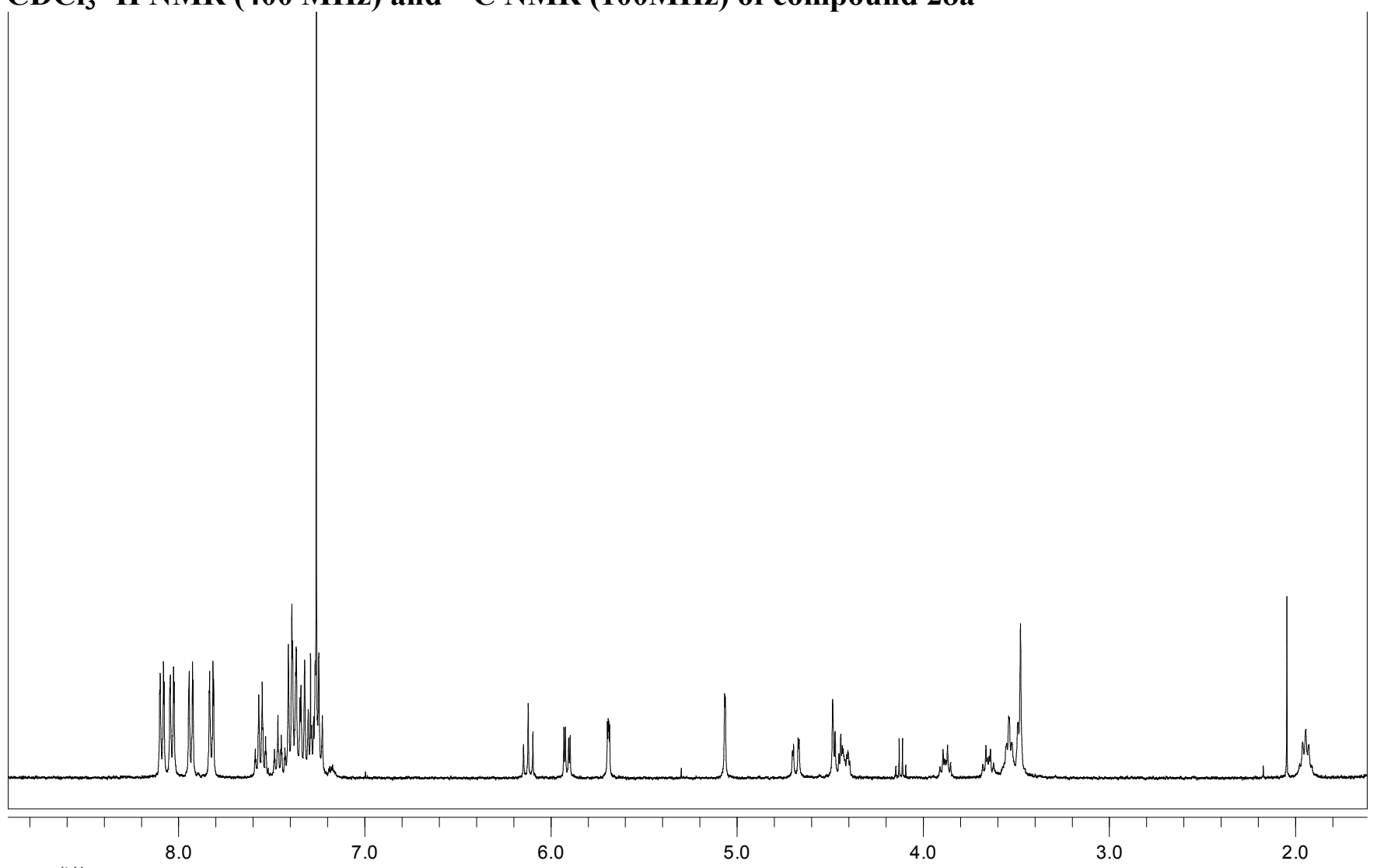

ppm (t1)

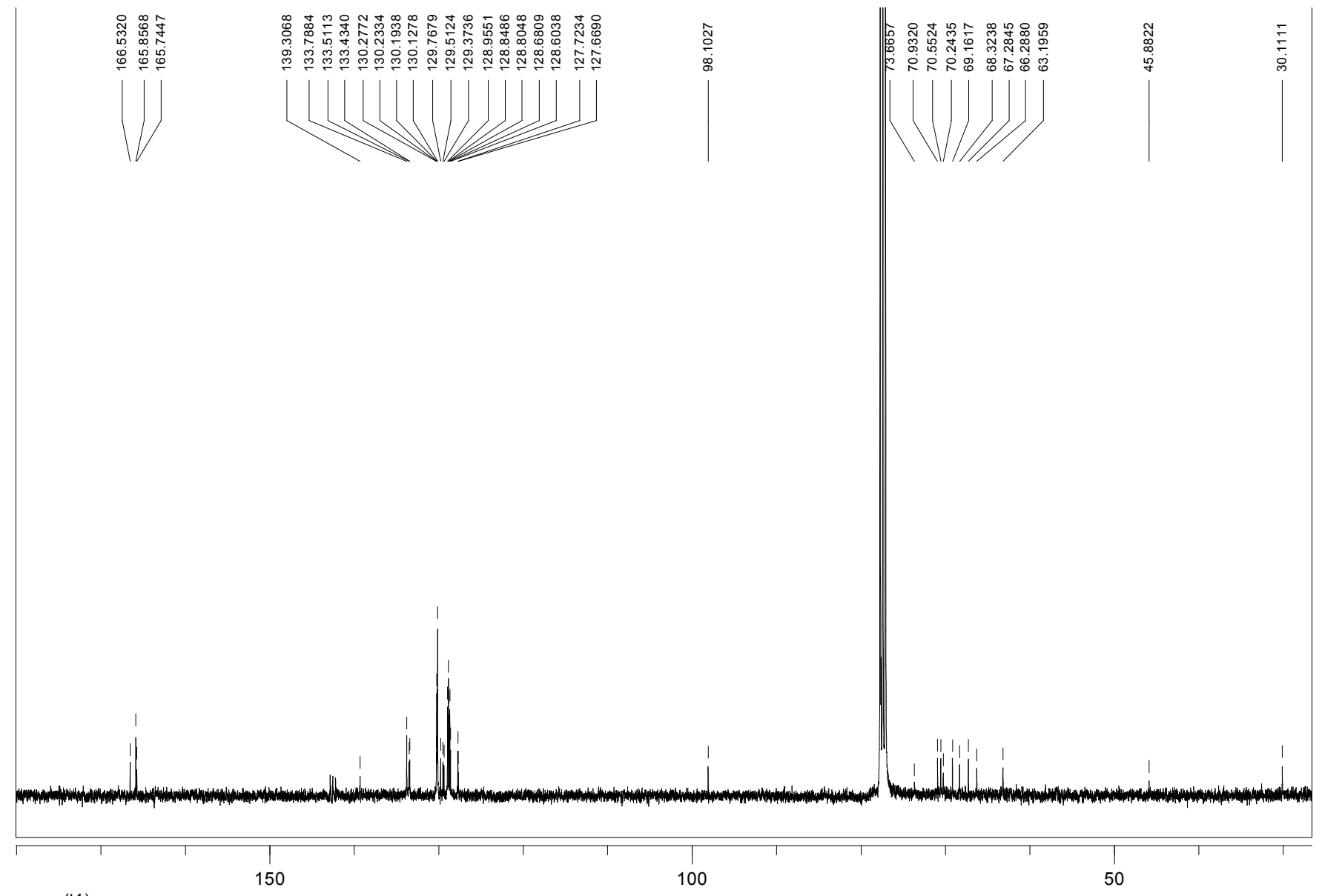

ppm (t1) 
$\mathrm{CDCl}_{3}{ }^{1} \mathrm{H}$ NMR (400 MHz) and ${ }^{13} \mathrm{C}$ NMR (100MHz) of compound $28 \mathrm{~b}$

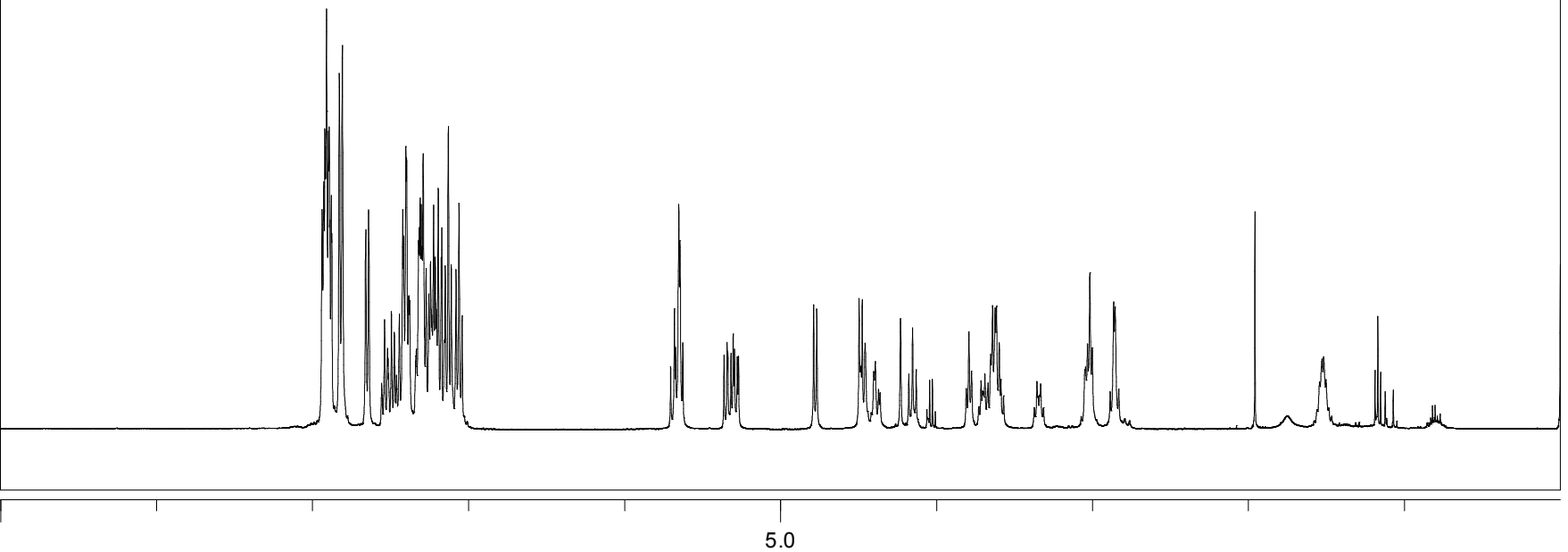

ppm (t1)

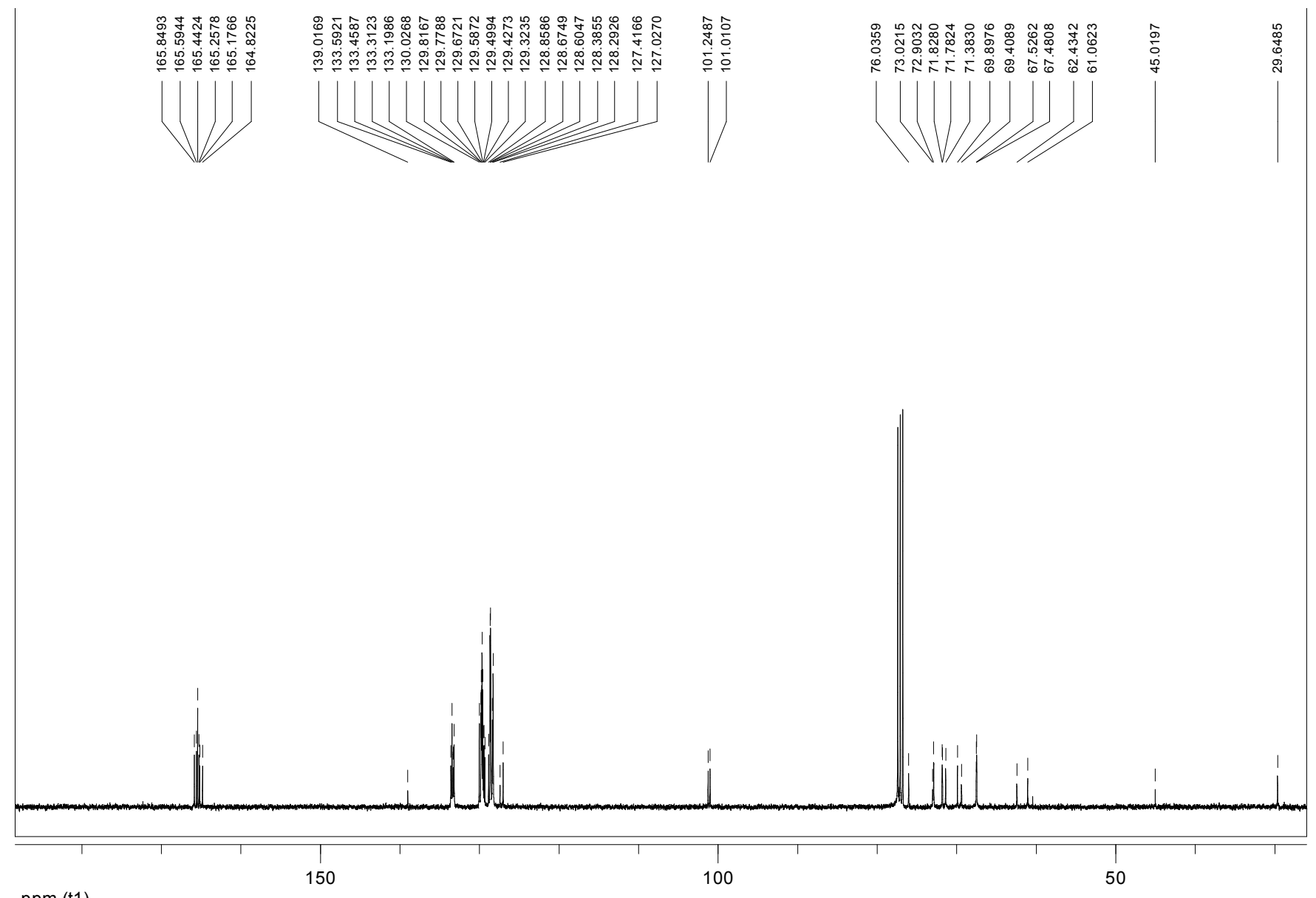

ppm (t1) 